\title{
EFFECTS OF SURFACE CHEMISTRY
}

\section{ON THE POROUS STRUCTURE OF COAL}

\author{
Quarterly \\ TECHNICAL PROGRESS REPORT \\ April 1996 - June 1996 \\ b y \\ Stasia A. Anderson \\ Patrick G. Hatcher \\ Fuel Science Program \\ Department of Materials Science and Engineering \\ The Pennsylvania State University \\ University Park, PA 16802
}

TERVED

$60123 \operatorname{sen}$

OSTI

Prepared for the U. S. Department of Energy

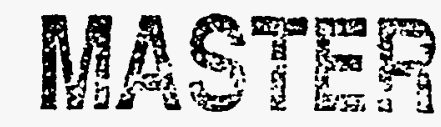

Grant No. DE-FG22-94PC94216 


\section{DISCLAMMER}

Portions of this document may be illegible in electronic image products. Images are produced from the best available original document. 


\section{DISCLAIMER}

This report was prepared as an account of work sponsored by an agency of the United States Government. Neither the United States Government nor any agency thereof, nor any of their employees, makes any warranty, express or implied, or assumes any legal liability or responsibility for the accuracy, completeness, or usefulness of any information, apparatus, product, or process disclosed, or represents that its use would not infringe privately owned rights. Reference herein to any specific commercial product, process, or service by trade name, trademark, manufacturer, or otherwise does not necessarily constitute or imply its endorsement, recommendation, or favoring by the United States Government or any agency thereof. The views and opinions of authors expressed herein do not necessarily state or reflect those of the United States Government or any agency thereof. 
TABLE OF CONTENTS

Page

Objectives.................................................................... 3

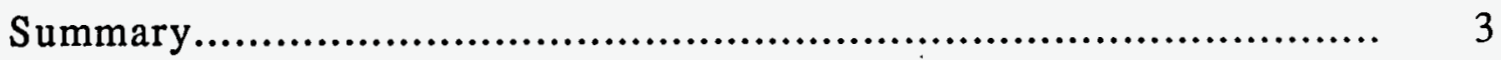

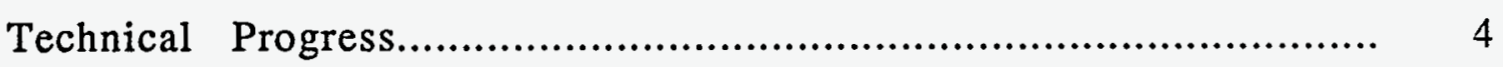

Future Plans ............................................................. 20

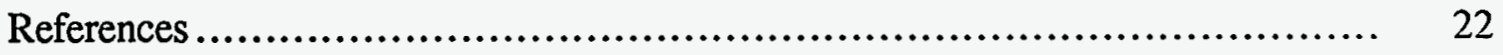

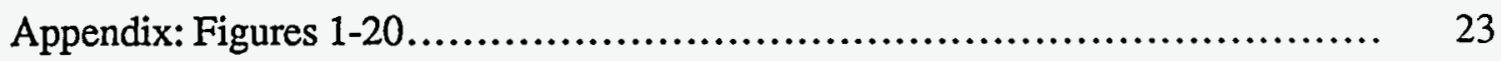

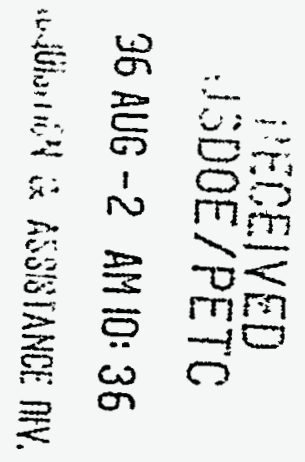




\section{OBJECTIVES}

The primary objective of this work is to use ${ }^{129} \mathrm{Xe}$ NMR to characterize the microporous structure of coals. We will use direct information on pore size, as well as indirect information from adsorption rates and evidence for intra/extra particle diffusion, to characterize the connectivity of the micropore network. A second objective is to use ${ }^{129} \mathrm{Xe}$ NMR to to describe the effect of controlled opening of the micropores in a microporous carbon by oxygen chemisorption/desorption.

\section{SUMMARY}

During this quarter, we have: (i) performed a presaturation experiment on Wyodak subbituminous coal; (ii) monitored the progress of xenon adsorption in an anthracite, focusing on the changed observed in the external-surface adsorbed gas signal, (iii) used an echo sequence to obtain ${ }^{129} \mathrm{Xe}$ NMR spectra of Blind Canyon hvAb coal; and (iv) improved and repeated the successive oxygen adsorption and desorption experiment on a microporous carbon, which had been first performed in the last quarter. 


\section{TECHNICAL PROGRESS}

\section{${ }^{129}$ Xe NMR spectra of a subbituminous coal with presaturation}

Introduction. The presaturation experiment is designed to determine whether the profile of the generally broad line of ${ }^{129} \mathrm{Xe}$ adsorbed in coal is due to the superposition of xenon signals from a number of adsorption sites that are similar enough that they are not resolved as individual signals. The differences in the adsorption sites could be due to a distribution of pore size and/or chemically different regions in the coal; both of which are very likely to exist. It has been speculated by Wernett (1991) that the ${ }^{129}$ Xe NMR peak profile describes the pore size distribution; however this hypothesis has not been tested.

Typical ${ }^{129} \mathrm{Xe}$ NMR spectra of coal are single broad signals, or signals with shoulders. We intend to establish whether or not the signal outline is due to a distribution of closely similar sites. The determination of whether the peak shape is due to the pore size distribution would be a significant advance in our ability to fully exploit the information about coal physical structure that is available through ${ }^{129} \mathrm{Xe}$ NMR. We are also investigating in a separate study, the possible influence of chemical shift anisotropy on the signal shape. It should be noted that both phenomena are possible and neither precludes the other.

In this study we will use a low power presaturation pulse before the high power pulse which gives the NMR spectum. The purpose of low power presaturation is to excite, to the point of saturation, only those ${ }^{129} \mathrm{Xe}$ atoms whose resonant frequency is in a narrow frequency band. Low power is used because the low power pulse is narrow, and this allows it to be applied selectively. This is a particularly good feature of the experiment for application to adsorbed xenon studies. 
The presaturation pulse is immediately followed by a $90^{\circ}$ high power pulse; this pulse is wide and excites xenon nuclei that resonate anywhere within the spectral region. This pulse causes a perturbation in the spin distribution of those nuclei at equilibrium, which leads to the NMR signal. However, nuclei that are already saturated are flipping between their nuclear spin states and continue to do so when the high power pulse is applied, contributing no signal.

All the atoms contributing to the spectrum, except those whose resonant frequency matched the presaturation pulse, will be able to contribute a signal. The net effect of this experiment is expected to differ depending on what is happening physically to the adsorbed xenon during the time the pulse is applied. The possibility that the xenon atom is to some degree mobile gives four possible scenarios.

1. The xenon atoms are in distinct sites and are effectively immobile in the relevant time frame: We would expect to see either a break or a dip in the outline of the adsorbed gas signal in the area where the low power pulse was applied.

2. The xenon atoms are in distinct sites but can diffuse among them in the relevant time frame: We would expect to see overall loss of the adsorbed gas signal intensity, which may be accompanied by a change in the signal shape.

[Note that 1. and 2. are in fact related in that they are only distinguished by the time frame of site to site diffusion. For example, if the xenon atoms sample all the sites in $200 \mathrm{~ms}$, they would probably appear immobile if saturated for $50 \mathrm{~ms}$. Variation of the time frame of the experiment can identify the transition from one effect of presaturation to another; thus, additional information on intraparticle (or site to site) diffusion rates are available from this experiment as well.]

3. The xenon atoms are diffusing to a significant extent, into and out of the particle: We would expect the intensity of both adsorbed and external-surface signals to decrease. 
4. The wide signal is not due to a distribution of sites, but to a short $\mathrm{T}_{2}$ and/or magnetic field inhomogeneity: The signal intensity could be decreased by presaturating the peak maximum, but the shape should remain the same, and presaturating the signal off center should have much less or no effect.

Experimental. A piece of Wyodak subbituminous coal was cut parallel to the bedding plane and inserted into a 10-mm NMR tube. The tube was then constricted, so that it could be flame sealed after preparing the sample. The sample was dried for 24 hours at $80^{\circ} \mathrm{C}$ and three days at room temperature, then charged with xenon to a pressure of about 800 torr and equilibrated four hours on the vacuum line. More xenon was added as adsorption progressed in order to keep the xenon pressure over 700 torr. The sample was then flamesealed.

NMR spectra were acquired on a Bruker AMX 360 NMR spectrometer operating at 99.61 MHz. A 60dB low power presaturation pulse was applied (at varying frequencies and for varying pulse lengths as described in the results and discussion section), followed by a $90^{\circ}$ pulse and $3 \mathrm{~s}$ delay. All spectra in this group were run for 400 scans. Xenon gas at 700 torr was used as an external chemical shift reference.

Results and Discussion. The first task was to demonstrate that enough power is applied in the presaturation pulse to cause saturation. Variation of the pulse length for the presaturation pulse was tested on the external-surface adsorbed gas peak at approximately 0 $\mathrm{ppm}$. The adsorbed gas peak was not used for this test because of the number of possible results of presaturating it; for this test we need a predictable result, which is the complete saturation of the signal. The external gas peak was presaturated by centering the 01 offset frequency on it, which centers the applied pulse on the signal. The experiment was run without presaturation to provide a reference, then with 100 and $200 \mathrm{~ms}$ presaturation pulse length centered on the external gas peak. Figure 1 illustrates the effect of increasing the 
pulse length. $100 \mathrm{~ms}$ of presaturation significantly decreased the intensity of the signal, and $200 \mathrm{~ms}$ gave close to complete suppression of it.

The second aspect of these spectra that it is important to note is whether the adsorbed gas peak at about $150 \mathrm{ppm}$ is affected by presaturating the $0 \mathrm{ppm}$ gas peak. The spectra in Figure 1 are all acquired for 400 scans, and their relative intensities can be compared - however, as printed, the spectra are all expanded so the largest peak is a given height. When they are observed together to the same scale on the NMR instrument, intensity loss in the adsorbed xenon peak is evident in both 100 and $200 \mathrm{~ms}$ presaturated spectra. (The increased noise in the presaturated spectra in Figure $\mathbf{1}$ are an indication that they are weaker overall than the reference spectrum.) Due to the signal to noise in these spectra, subtle differences in the adsorbed signal shape are not taken to be significant. More scans will be taken to determine whether change in signal shape occurred. In addition, a reference spectrum will be acquired with a presauration pulse centered far from the xenon signals; our current reference has no presaturation.

We next presaturated three sections of the adsorbed gas peak, centering a $100 \mathrm{~ms}$ low power pulse at 22,000,20,000, and $19,000 \mathrm{~Hz}$ ( 167,147 , and $135 \mathrm{ppm})$, Figure 2. At $167 \mathrm{ppm}$, the signal shape is substantially the same as the reference spectrum. The signal intensity, relative to the external-surface adsorbed gas signal at about $0 \mathrm{ppm}$, is decreased compared to the reference. When presaturated at $135 \mathrm{ppm}$, a marked shoulder appears and the signal as a whole is suppressed more than it is for irradiation at $167 \mathrm{ppm}$. Presaturation at $147 \mathrm{ppm}$ also produces a distinct shoulder, as well as the most overall signal suppression of the group.

We last tested the effect of increasing the low power pulse length. Pulses of 100 , 200 and $300 \mathrm{~ms}$ were applied at $19,000 \mathrm{~Hz}(\sim 135 \mathrm{ppm})$, Figure 3. All three spectra display a pronounced shoulder. Increasing low power pulse length to $300 \mathrm{~ms}$ does not have a marked effect. Using $200 \mathrm{~ms}$ presaturation, the shoulder appears more distinct than 
for $100 \mathrm{~ms}$, and this would be expected given that $100 \mathrm{~ms}$ gives less than complete saturation of the gas signal in Figure 1. Increasing to $300 \mathrm{~ms}$ did not make a noticable difference. The signal to noise in these spectra is not good enough to compare more subtle differences in the signal outlines; spectra will be acquired with more scans for all experimental conditions of interest.

We expect the effect of increasing the low power pulse length to be sensitive to the dimensions of the solid. This experiment was conducted on a whole piece of coal about 1 $\mathrm{cm}$ in diameter and $3 \mathrm{~cm}$ in length. Due to the dimensions of this sample, the diffusion path length of adsorbed xenon is not as likely to be on the order of the dimensions of the solid as it could be if adsorbed in a powder. This experiment will be run using a powdered sample in order to utilize the potential of this experiment to identify diffusion time frames.

Overall, the presaturation experiments indicate that there is some diffusion of the external gas into the solid in 100 to $200 \mathrm{~ms}$. Adsorbed gas signal shape alteration due to presaturating certain parts of the signal could mean a "hole" was burned in those sections and that those sections of the signal were from xenon adsorbed in distinct adsorption sites. The entire signal outline, however, does not respond in the same way, indicating that the whole outline does not arise from the adsorption site distribution.

Suppression of the overall adsorbed signal intensity occurred whenever the adsorbed signal was presaturated. This indicates site to site diffusion occurs within the presaturation time, but needs further study because presaturating the external gas signal also suppresses the adsorbed gas signal; thus, the diffusion of non presaturated xenon atoms into the solid has to be taken into account. The greater effect on overall signal intensity from presaturation of 147 compared to $167 \mathrm{ppm}$ indicates that some coal regions may have faster site to site diffusion than others. This experiment is very promising and will be continued. The emphasis of the next experiments will be on presaturation pulse 
length effect using size-graded particles. We will also determine whether the shape change induced is in fact a spectral "hole" or some other effect.

\section{${ }^{129} \mathrm{Xe}$ NMR as a technique to follow the adsorption process}

Introduction. One goal of this project is the investigation of new applications of ${ }^{129} \mathrm{Xe}$ NMR to the study of coals and carbons. In this study we are considering the possible utility of using ${ }^{129} \mathrm{Xe}$ NMR to track the xenon adsorption process. We are interested in what may be revealed about the rate of approach to equilibrium and the determination of achievement of equilibrium, particularly if there are changes detectable by NMR (e.g., gas location within the porous network) which are not apparent from gas uptake vs. time data. Lykens Valley anthracite was used as the adsorbent.

In the initial run of this experiment, performed in the last quarter, we observed an external surface adsorbed gas peak in the larger particle size spectra in the earlier times. This signal had disappeared by the 20 hour spectrum. In the smaller particle size sample, which was prepared at the same initial pressure, the external surface signal was not observed at any time; nor was it observed in our spectra of -60 mesh anthracite. In this run, spectra were taken more frequently in order to locate the time of disappearance of the $0 \mathrm{ppm}$ gas signal, and to be able to inspect the features of the spectra from that time period.

Experimental. A 40-60 mesh particle size fraction of Lykens Valley anthracite was dried 6 hours at $100^{\circ} \mathrm{C}$ and 24 hours at room temperature in a $10 \mathrm{~mm}$ NMR tubes fitted with a Rototite valve (Wilmad). The sample was charged with xenon gas to a pressure of $\sim 650$ torr and not allowed to equilibrate; the tube was sealed and removed from the manifold within one minute. NMR spectra were acquired on a Bruker AMX 360 NMR spectrometer operating at $99.61 \mathrm{MHz}$. Spectra were acquired at progressively increasing time intervals ranging from approximately 7 minutes to 2 hours were acquired on individual samples over 
a 15 hour period, with an additional spectrum taken at 24 hours. A $90^{\circ}$ pulse width was employed with $2 \mathrm{~s}$ delay. In order for each spectrum to represent a short window of time, 160 scans were taken per spectrum, which was the minimum number of scans necessary to obtain adequate signal-to-noise. Xenon gas at 700 torr was used as an external chemical shift reference.

Results and Discussion. The spectra bracketing the time of the disappearance of the external-surface adsorbed gas peak are shown in Figure 4. Chemical shift and linewidth were plotted as functions of time, Figure 5. Xenon uptake by the 40-60 mesh sample was not measured separately in this run.

Observation of the external-surface gas peak during the adsorption process. This experiment follows what happens to two NMR signals in the spectra of Lykens Valley anthracite during the process of xenon adsorption. This is the first direct observation of the time dependent changes in these signals. The spectra illustrate the progress of the externalsurface adsorbed gas signal from its maximum intensity when the sample is first dosed with xenon, to its reduction as the adsorbed gas signal grows, to its disappearance at about 6 hours.

The spectra bracketing the time of the disappearance of the external-surface adsorbed gas peak are shown in Figure 5. The exchange of intensity that is observed over time between the external and adsorbed signals confirms that the spectra show passage of xenon from the outside in. The large particle size apparently has a slow enough uptake that this observation is possible. In the -100 mesh size, the external gas signal was never observed.

The peculiarity of the anthracite compared to the other coals in this study is that it is the only one for which the external gas signal is usually not detected in the NMR spectra. There are a number of possible reasons for this. Lack of a $\sim 0 \mathrm{ppm}$ signal could be due to 
gas uptake by the sample that is so large that what remains free in the NMR tube is too little to detect. We have not observed this signal in Spherocarb, for example, which is a very high $\left(900 \mathrm{~m}^{2} / \mathrm{g}\right)$ surface area carbon. The surface area of Lykens Valley anthracite is less than $200 \mathrm{~m}^{2} / \mathrm{g}$, however, not very different from the rest of the coal group. In earlier experiments, spectra of -60 mesh anthracite brought to equilibrium on the manifold, where the pressure is monitored, show no 0 ppm gas signal even for pressure in the NMR tube up to 650 torr.

It is possible that the "external" signal is not from open surface but from macro or mesoporosity, where the pore wall separation is large enough that the xenon signal there is primarily free-gas-like, but small enough to decrease the xenon $T_{1}$. (It has not been established what exactly the cutoff dimensions would be, and if they vary with chemical makeup of the solid.) Loss of a signal from larger pores while the signal from smaller pores increases could mean the larger are the route of access to the smaller. It is unclear, however, if in this case the subsequent loss of signal from larger pores as adsorption progressed would be logical. This will be discussed further when we have more information.

The spectrum at the time the $0 \mathrm{ppm}$ signal disappears has an anomalously large linewidth for the adsorbed gas signal (point at 5.75 hours in Figure 5 (b)). This single outlying point could be due to outside factors, but if it is real, may indicate the occurrence of an "event" in the adsorption process that corresponds to the disappearance of the $0 \mathrm{ppm}$ signal. This signal had been steadily shrinking and this implies a gradual process. Without more information, we can only speculate about what may be occurring. We plan to investigate this topic further.

Reproducibility of the time dependence of chemical shift and linewidth during xenon adsorption by 40-60 mesh anthracite.The first and second runs of the 40-60 mesh sample were compared to determine how reproducible the time dependence of the NMR parameters 
are. Table 1 lists the time constants for the exponential decays, and summarizes the times at which the plots for the first and second runs of this sample show transition from fast to slow change (bend), and when they have flattened out.

Table 1. Comparison of characteristic times for time-dependent chemical shift (CS), and linewidth (LW) for first and second run of 40-60 mesh Lykens Valley anthracite.

\begin{tabular}{|l|l|l|l|l|l|l|}
\hline $\begin{array}{l}\text { Sample } \\
\text { mesh }\end{array}$ & $\begin{array}{l}\text { CS time } \\
\text { constant }\end{array}$ & CS bend & $\begin{array}{l}\text { CS } \\
\text { flattens }\end{array}$ & $\begin{array}{l}\text { LW time } \\
\text { constant }\end{array}$ & LW bend & LW \\
\hline $\begin{array}{l}40-60 \\
\text { run 1 }\end{array}$ & $-16.7 \mathrm{ppm}$ & $4-6 \mathrm{hrs}$ & $>15 \mathrm{hrs}$ & $-1370 \mathrm{~Hz}$ & $2-3 \mathrm{hrs}$ & $>10 \mathrm{hrs}$ \\
\hline $\begin{array}{l}-40-60 \\
\text { run 2 }\end{array}$ & -8.29 & $3-5 \mathrm{hrs}$ & $>12 \mathrm{hrs}$ & -1163 & $1-2 \mathrm{hrs}$ & $>8 \mathrm{hrs}$ \\
\hline
\end{tabular}

The second run of this experiment has more scatter in the data, approaches equilibrium faster than the first run, and reaches the same ultimate chemical shift value, about $122 \mathrm{ppm}$ compared to 122 to $125 \mathrm{ppm}$ for both particle sizes in the first run. The time frame in which changes occur for the large particle size are somewhat faster but broadly consistent with the first run.

The experiment appears to be roughly, but not closely, reproducible. This could be inherent in the design, especially in terms of data scatter. The low number of scans keeps the time period covered by any one spectrum short, which is desirable, but also gives a noisy spectrum. The noise adds error to each chemical shift or linewidth measurement. It is expected, however, not to seriously effect the identification of the general trend in these measurements for a large enough group of spectra. 
The additional work performed has not changed the conclusion we drew initially. In our first investigation we demonstrated that there is a marked particle size effect on the rate of achievement of equilibrium adsorption of xenon by an anthracite. Between the two particle sizes, 40-60 mesh and -100 mesh, the chemical shift equilibria were reached 10+ hours apart, and linewidth equilibria were reached about 6 hours apart. These exceed the approximately two hour spread in the chemical shift and one hour spread in the linewidth times to reach equilibrium that we encontered in rerunning the 40-60 mesh sample.

The particle size effect is consistent with the earlier work of Radovic and coworkers (Menon et al. 1993; Radovic et al. 1996). In agreement with the interpretation offered there, and elsewhere (Mahajan, 1991; Walker and Mahajan, 1993), it is taken to represent support for the open-but-constricted microporous structure of coal. If diffusion of xenon occurred by dissolution into the solid matrix, such severe particle size effects would not be observed.

\section{${ }^{129} \mathrm{Xe}$ NMR spectra obtained using an echo sequence}

Introduction. We have, in the course of this project, examined six coals by ${ }^{129} \mathrm{Xe}$ NMR using a straightforward "zg" $90^{\circ}$ pulse and acquire pulse sequence. This has worked well for some coals, especially those of higher rank. In lower rank coals with broad, not especially strong signals, deformation of the baseline from acoustic ringing of the probe made the spectra difficult to phase. In the case of Blind Canyon hvAb coal, baseline ringing combined with a weak adsorbed xenon signal resulted in unacceptably poor spectra. It is necessary to separate the xenon signal from the acoustic ringing. To do so we have examined Blind Canyon using an echo pulse sequence, based on the Carr-PurcellMeiboom-Gill echo experiment (Carr and Purcell 1954; Meiboom and Gill 1958)). The 
generation of the "echo" of the xenon signal allows a time delay from the last pulse applied; during this time the probe ringing can decay without being incorporated into the FID.

Experimental. Blind canyon hvAb coal , -60 mesh, was obtained from the Penn State/DOE coal sample bank. The sample was prepared in a $10 \mathrm{~mm}$ NMR tube with Rototite valve (Wilmad) attatched to the vacuum line. It was dried overnight at $80^{\circ} \mathrm{C}$ and about 6 hours at room temperature, then charged with xenon and equilibrated one hour on the vacuum line. The sample was prepared at a total of five xenon pressures from 400 to 600 torr. The sample was held about 40 minutes under vacuum at room temperature between xenon doses.

NMR spectra were acquired on a Bruker AMX 360 NMR spectrometer operating at $99.61 \mathrm{MHz}$. A $90^{\circ}$ pulse was applied followed by a $50 \mu$ s delay, a $180^{\circ}$ pulse, and a $50 \mu \mathrm{s}$ delay. The recycle delay was $5 \mathrm{~s}$. Spectra in this group were run for 1500 to 4000 scans. Xenon gas at 700 torr was used as an external chemical shift reference.

Results and Discussion. The Blind Canyon hvAb coal echo spectra are shown in Figure 6. The baselines were free from deformation and the adsorbed gas signal at about $170 \mathrm{ppm}$ was more easily distinguishable than it was in spectra acquired using a $90^{\circ}$ pulse only. Interestingly, the xenon signal does not appear to be pressure dependent in this pressure range (400 to 600 torr). The chemical shift vs. xenon pressure plot is shown in Figure 7. This is the only instance we have encountered in our sample set of a pressure invariant signal.

Wernett et al.(1990) report one pressure invariant ${ }^{129} \mathrm{Xe}$ NMR signal, out of two adsorbed gas signals from xenon adsorbed in an Argonne Illinois \#6 coal. Their interpretation was that it may have been due to xenon adsorbed in the solid matrix of the coal. While this is possible, it is not the best explanation for the Blind Canyon sample. There is only one xenon NMR signal, aside from the free gas signal, in the spectrum. The 
$\mathrm{CO}_{2}$ surface area of Blind Canyon is $121 \mathrm{~m}^{2} / \mathrm{g}$, the lowest of our sample set, but still indicative of a microporous material. If there was a signal from xenon in the solid matrix of this sample, there would also have to be one from adsorption in the coal porosity. The single signal seen is very likely from xenon in the porous network.

It is possible for the Blind Canyon that the effect is due to constriction of the porosity either throughout the coal or at the particle surface (for example, due to oxidation). While all the coals are likely to have constricted micropores, it appears to be more extreme in this sample. Blind Canyon is $82 \% \mathrm{C}$ and falls in the range of rank where many studies have shown that surface area and porosity decrease compared to earlier ranks (see for example, Gan et al. 1972, Franklin 1949). This may be due to a plastic phase in the coalification process at about $85 \% \mathrm{C}$, with movement of the macromolecular components of coal (Hirsch 1954) Possibly this creates blockages in the coal porosity that had existed in earlier stages of coalification.

\section{Pore structure changes in a microporous carbon following oxygen chemisorption and desorption}

Introduction. The changes in the ${ }^{129} \mathrm{Xe}$ NMR signal for xenon adsorbed on a microporous carbon after successive oxidation and oxygen desorption steps were observed a second time in an effort to describe the effect of oxidation/desorption treatments on the pore size and/or structure of the carbon. This study was designed to confirm (or disprove) the intuitively obvious decrease in micropore diameter when oxygen functional groups 'decorate' the pore walls following oxidation, and increase, with possible removal of pore constrictions, when these groups are decomposed as $\mathrm{CO}$ and $\mathrm{CO}_{2}$. 
We determined that the results of the first run of this experiment required confirmation and have repeated the experiment. Two changes in procedure were made for the second run.We have measured the weight of xenon taken up in addition to recording the equilibrium pressure, and we have pretreated the as-recieved Spherocarb by heating at 250 ${ }^{\circ} \mathrm{C}$ under $\mathrm{N}_{2}$.

Experimental. Spherocarb 60-80 mesh (Phase Separations, Norwalk CT) was obtained and ${ }^{129} \mathrm{Xe}$ NMR spectra were acquired after each successive treatment as follows: asrecieved Spherocarb pretreated, oxidized (oxidation 1), desorbed (desorption 1), oxidized (oxidation 2), desorbed (desorption 2). Oxidation and desorption were carried out in a Thermolyne 21100 tube furnace. As-recieved Spherocarb was pretreated at $250^{\circ} \mathrm{C}$ under $\mathrm{N}_{2}$ for two hours. The sample was oxidized by heating in a shallow tray at $250{ }^{\circ} \mathrm{C}$ for $4-5$ hours. Air flow was $170 \mathrm{~mL} / \mathrm{min}$. The sample was cooled under air, weighed, and examined by NMR. The sample was desorbed by heating to $850{ }^{\circ} \mathrm{C}$ under $200 \mathrm{~mL} / \mathrm{min} \mathrm{N}_{2}$. The sample was then cooled under nitrogen, removed, weighed, and examined by NMR. Subsequent oxidation/desorption was carried out on the same sample, so that the changes produced in the sample are cumulative.

${ }^{129} \mathrm{Xe}$ NMR spectra were acquired on a Bruker AMX 360 NMR spectrometer operating at $99.61 \mathrm{MHz}$. A $90^{\circ}$ pulse was applied with 2s delay. Spectra in this group were run for 40 to 80 scans. Xenon gas at 700 torr was used as an external chemical shift reference.

Results and Discussion. ${ }^{129} \mathrm{Xe}$ NMR spectra were acquired at a series of pressures for each sample treatment, Figures 8 to 12. Chemical shift vs. xenon uptake $(\mathrm{g} \mathrm{Xe} / \mathrm{g}$ sample) were plotted for each treatment of the sample, Figure 13. The slopes and interepts of chemical shift vs. xenon uptake plots are compared to sample treatment in Figure 14, and slope vs. intercept is plotted in Figure 15. Uptake $(\mathrm{g} / \mathrm{g})$ of xenon was 
plotted vs. pressure, and shown with chemical shift vs. pressure for each sample in Figures 16 to 20.

Pretreatment of as-recieved Spherocarb. In the first run of this experiment, reported in Quarter 6, the pore size calculation showed a small (3\%) weight loss and an apparent increase in pore size from untreated sample to oxidation 1 , which may indicate desorption occurred of functional groups that are unstable at $250^{\circ} \mathrm{C}$ (e.g., carboxyl groups). In this, second run, pretreatment of unoxidized Spherocarb was carried out by heating to $250^{\circ} \mathrm{C}$ in $\mathrm{N}_{2}$ before examining it by NMR. From pretreated sample to oxidation 1 , there was a very small weight loss $(0.8 \%)$. The calculated pore size decreased, which would be expected if oxygen functional groups were added to the pore walls.

The results indicate that some constituent of the as-recieved Spherocarb is labile at $250^{\circ} \mathrm{C}$. Desorbing these beforehand prevents their desorption during the first oxidation, and thereby prevents uncertainty in the cause of the weight change upon the first oxidation.

Pressure dependence of the ${ }^{129} \mathrm{Xe}$ chemical shift and its variation with sample treatment.

The pattern in change of intercept with sample treatment is that oxidation increases the intercept, as would be expected after addition of oxygen functional groups to the pore walls. Desorption decreases the intercept relative to the previous oxidation, in agreement with the expected trend after the the removal of oxygen functional groups from pore walls. This pattern held throughout the series.

The chemical shift extrapolated to zero pressure from the chemical shift vs. pressure plot (the intercept) is used to calculate the pore diameter by the method of Demarquay and Fraissard (1987). It represents that portion of the chemical shift that is due to the xenonpore wall interaction. Larger values correspond to smaller pore sizes and vice versa. A decreasing intercept indicates an increasing pore size. This is applicable in the pore size range in which the chemical shift vs. pressure plot is linear, up to about $20 \AA$. 
Pore diameters were calculated from the intercept $\left(\delta_{0}\right)$ of the chemical shift vs. pressure plot, following the method of Demarquay and Fraissard (1987).

mean free path $\mathrm{I}$ of Xe in the pore (in $\AA$ ): $\quad I=\frac{(243)(2.054)}{\delta_{0}}-2.054$ pore diameter $\mathbf{d}$, assuming a cylindrical pore (in $\AA$ ): $\quad \mathbf{d}=\mathbf{l}+4.4$

The calculated pore sizes for each treatment of Spherocarb are listed in Table 2 . Calculated pore diameter decreases in the oxidized samples, consistent with the expected decrease in pore wall diameter when oxygen functional groups are added. There was increase in calculated pore diameter after each desorption. However, the pore diameter was greater in the first than in the second desorption. A similar effect was noted in the first run of this experiment, although we will not be comparing the results directly due to changes in procedure for the second run. We hypothesize that by the second desorption there may have been destruction of an outer layer on the Spherocarb particles, possibly opening previously inaccessible porosity.

Table 2. Pore diameter calculations for oxygen chemisorption and desorption of Spherocarb, run 2.

\begin{tabular}{|l|c|c|c|c|c|}
\hline & $\begin{array}{l}\text { as } \\
\text { received }\end{array}$ & $\begin{array}{c}\text { oxidation } \\
1\end{array}$ & $\begin{array}{c}\text { desorption } \\
1\end{array}$ & $\begin{array}{c}\text { oxidation } \\
2\end{array}$ & $\begin{array}{c}\text { desorption } \\
2\end{array}$ \\
\hline $\begin{array}{l}\text { Weight } \\
\text { change, \% }\end{array}$ & $\mathrm{n} / \mathrm{a}$ & -0.8 & -17 & +7.6 & -15.3 \\
\hline $\begin{array}{l}\text { intercept, } \\
\text { ppm }\end{array}$ & 46.96 & 55.60 & 44.07 & 53.43 & 51.55 \\
\hline $\begin{array}{l}\text { Diameter, } \\
\AA\end{array}$ & 13.0 & 11.3 & 13.7 & 11.7 & 12.0 \\
\hline
\end{tabular}


The slope of the chemical shift vs. pressure plot is less easily interpreted than the intercept. It is logical to consider larger pores, or those with less constrictions, as more accessible to xenon; thus more may enter a larger pore for a given pressure increase, resulting in a steeper variation of chemical shift with pressure (i.e., a greater slope). Based on our previous work, there also remains the possibility that the slope is directly related to the surface area, as preliminary results on coal have indicated. The possible correlation of slope and surface area is compatible with the concept of steeper slope indicating a more open porosity as well. When the coal surface area measurements are completed, we will detemine whether the new data support the preliminary indications.

In this study, increases in intercept of chemical shift vs. xenon uptake $(\mathrm{g} / \mathrm{g}) \mathrm{did}$ not correspond to decreases in slope, as shown in Figures 14 and 15. The slope and intercept did correlate in the first run of this experiment, using pressure rather than weight based data. This was not reproduced in either uptake or weight based data in the second run. Further analysis will be required before we can determine whether this experiment can shed light on the significance of the slope to pore structure. We will be concentrating initially on whether the uptake/slope dependence in Figure 15 can be separated into two linear sets, based on the possibility that due to the sample treatments, the material had two chemically and/or physically different forms.

One consideration is that in the Spherocarb sample set we have presumably produced two subgroups of differing wall chemistry: one with pore walls lined with oxygen functional groups (the oxidized samples), and one lined with primarily carbon atoms (the desorbed samples). This apparently does not affect the slope/uptake relationship, at least in that it cannot be separated into linear sets on the basis of sample oxidation. The slope/uptake relationship can, however, be separated into two linear sets on the basis of time order of treatments. One strong possibility we will be considering is that at some point in the process of sample treatment, we have removed or significantly altered 
one component of a two component material. Our final analysis of this problem is not complete at this time.

Comparison of xenon density and xenon pressure measurements and their correspondence to chemical shift. Xenon pressure and weight taken up by the sample were measured at thirty minutes adsorption time. The plots of xenon uptake in grams correspond very well to the chemical shift in all samples in this experiment, correlation coefficients 0.99 or better. The xenon pressure is less close with correlation coefficients (r) in the range 0.90 to 0.99 with one sample not linear (desorption 1, Figure 18). Desorption 2, Figure 20, is shown with a polynomial fit with $\mathrm{r}=0.86$. A linear fit for this sample gives $\mathrm{r}=0.81$.

Comparison of the isotherms (xenon uptake vs. pressure, $298 \mathrm{~K}$ ) in Figures 16 20 with the chemical shift vs. pressure plots shows that they are virtually identical; this comes from the very close correspondence of xenon uptake $(\mathrm{g} / \mathrm{g})$ to chemical shift. Thus even for the desorption 1 and 2 samples chemical shift data is a linear function of xenon uptake.

The data have the interesting result that the chemical shift vs. pressure plot follows the same pattern as the isotherm at room temperature, in the pressure range we have studied. The results also show that the uptake data are more reliable than equilibrium pressure, unless the sample isotherm at the experimental temperature is known.

\section{FUTURE PLANS}

Chemical shift anisotropy in coal. Determination of whether chemical shift anisotropy exists for xenon adsorbed in coal is our next experimental priority. We will acquire Magic Angle Spinning spectra of three to five powdered coals representing a range 
of rank. The use of magic angle spinning in a solids NMR probe is the most widely accepted method to verification of the existence of chemical shift anisotropy. This experiment has the potential to add new information to the well known $\mathrm{x}$-ray diffraction work of Hirsch (1954), as well as other studies, which indicate a sudden and quite intriguing change in the physical structure of coal around $88 \% \mathrm{C}$.

$T_{1}$ for dissolved xenon (no empty space) $v s . T_{1}$ in microporous solids. This study is currently in progress. It is intended to provide a method to differentiate xenon NMR signals arising from dissolved vs. adsorbed xenon. Relaxation time is an indicator of molecular (or atomic in the case of xenon) mobility, and thus could be significantly different for xenon dissolved in a solid matrix as opposed to that adsorbed on a surface or in a pore. Such a method would be useful to validate, or invalidate, the assertion of Larsen et al. (1995) that most adsorbates must dissolve in and diffuse through 'solid' coal to reach most of the microporosity.

We have examined four coals and one microporous carbon. We intend to examine xenon dissolved in a liquid and in an amorphous polymer, and then to determine whether significant differences in $\mathrm{T}_{1}$ can be ascribed to materials on the basis of having, or not having, microporosity. Preliminary results indicate the nonporous material does not take up xenon under conditions used for the coals; this in itself may hold the answer to the question of whether xenon is absorbed or adsorbed in coal. We will discuss this experiment in the next quarter.

Low power presaturation:: As discussed earlier in this report, we will continue our investigation of the effect of low power presaturation on the adsorbed xenon NMR signal. Use of size graded powdered coal samples will allow diffusion effects to be quantified with this method. It may not be necessary to use another method we had considered to delineate intra/extra particle exchange effects, which was selective saturation transfer. 


\section{REFERENCES}

Carr, H. Y., and Purcell, E. M., Phys. Rev. 94, 630 (1954).

Demarquay, J. and Fraissard, J. Chem. Phys. Lett. 136, 314 (1987).

Franklin, R. E., Trans. Faraday Soc. 45, 274 (1949).

Gan, H., Nandi, S. P., and Walker, P. L. Jr., Fuel 51, 272, (1972).

Hirsch, P. B. Proc. Royal Soc., (London) A226, 143 (1954).

Larsen, J. W., Hall, P., and Wernett, P. C. Energy Fuels 9, 324 (1995)

Mahajan, O. P., Carbon 29, 742 (1991)

Meiboom, S. and Gill, D. Rev. Sci. Instr. 29, 688 (1958).

Menon, V. C., Kyotani, T., Danner, R. P., and Radovic, L. R. Proc. 7th International Conference on Coal Science, ( K. H. Michaelian, Ed.),Vol.I, Banff, Alberta, Canada, p. 398 (1993)

Radovic, L. R., Menon, V. C., Leon y Leon, C. A., Kyotani, T., Danner, R. P., Anderson, S., and Hatcher, P. G. Adsorption, accepted 4/96.

Walker, P. L. Jr., and Mahajan, O. P. Energy Fuels 7, 559 (1993).

Wernett, P. C., Larsen, J. W., Yamada, O., and Yue, H. J., Energy Fuels 4, 412 (1990). 
APPENDIX 

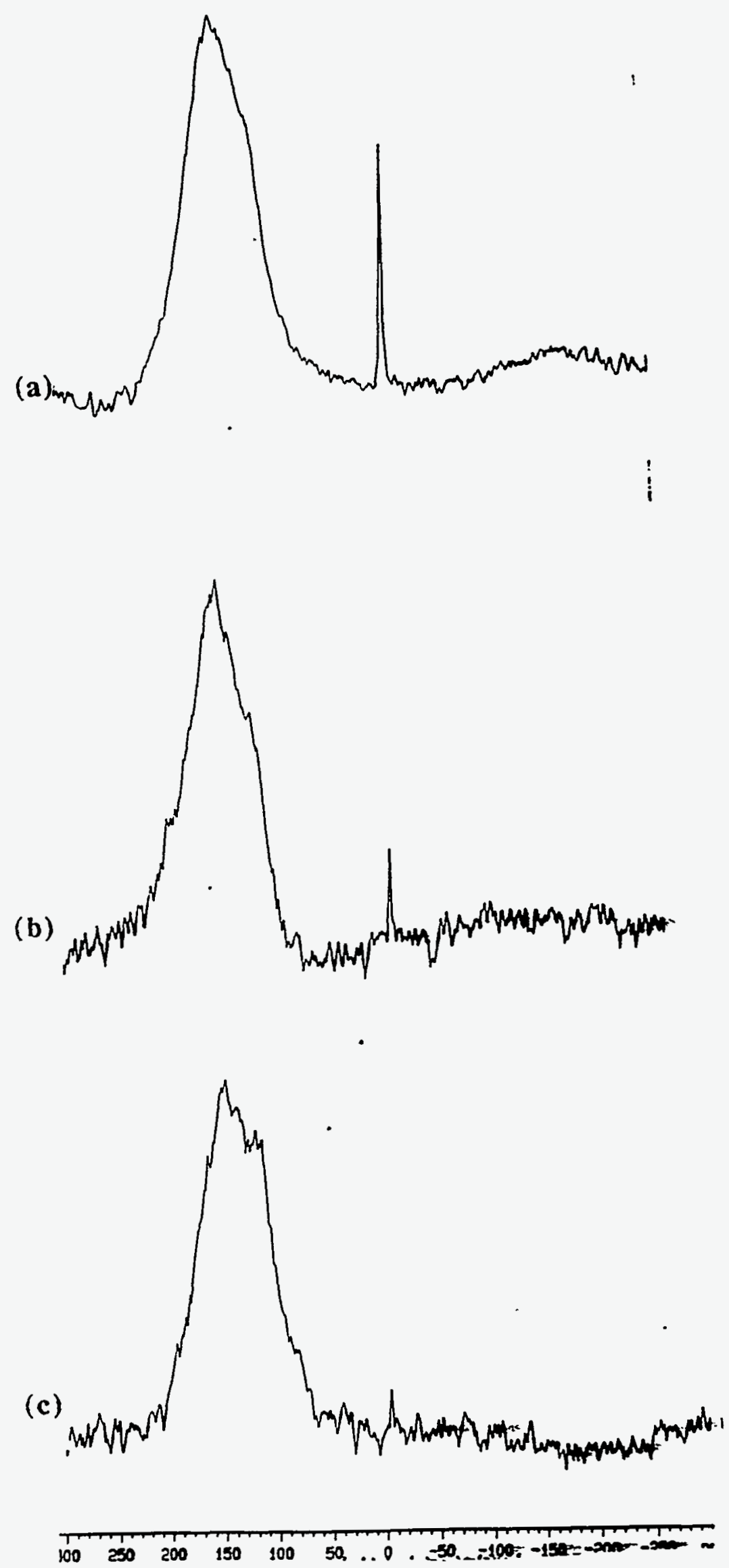

Figure 1. ${ }^{129} \mathrm{Xe}$ spectra of Wyodak subB coal (a) without presaturation, and with low power presaturation at $5221 \mathrm{~Hz}(\sim 0 \mathrm{ppm})$ for (b) $100 \mathrm{~ms}$ and (c) $200 \mathrm{~ms}$. 

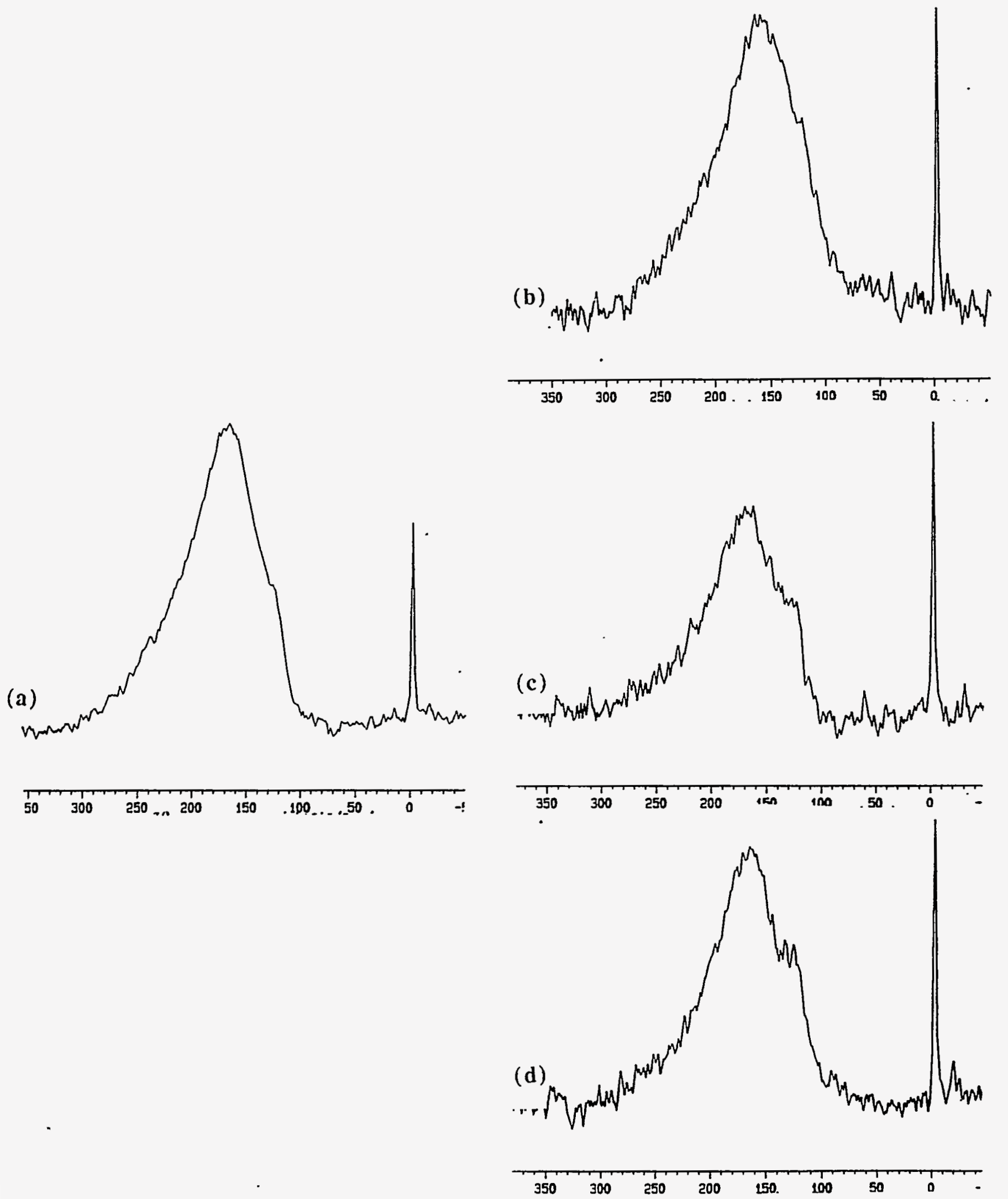

Figure 2. ${ }^{129} \mathrm{Xe}$ spectra of Wyodak subB coal (a) without presaturation, and with low power presaturation for $100 \mathrm{~ms}$ at (b) $22,000 \mathrm{~Hz}$ ( $167 \mathrm{ppm})$, (c) $20,000 \mathrm{~Hz}$ ( 147 ppm), and (d) $19,000 \mathrm{~Hz}(\sim 135 \mathrm{ppm})$. 

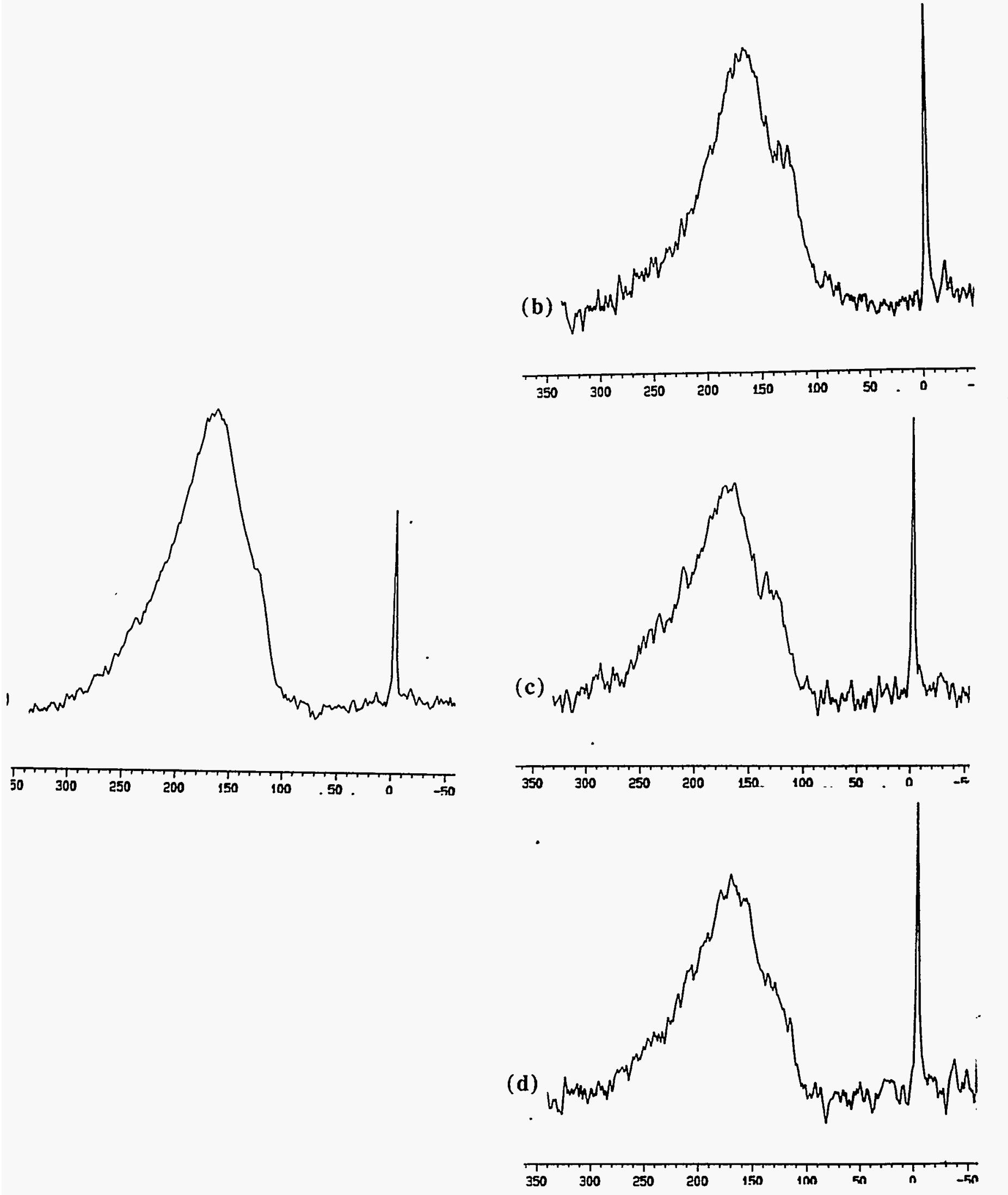

Figure 3. ${ }^{129} \mathrm{Xe}$ spectra of Wyodak subB coal (a) without presaturation, and with presaturation at $19,000 \mathrm{~Hz}(\sim 135 \mathrm{ppm})$ for (b) $100 \mathrm{~ms}$, (c) $200 \mathrm{~ms}$, and (d) $300 \mathrm{~ms}$. 


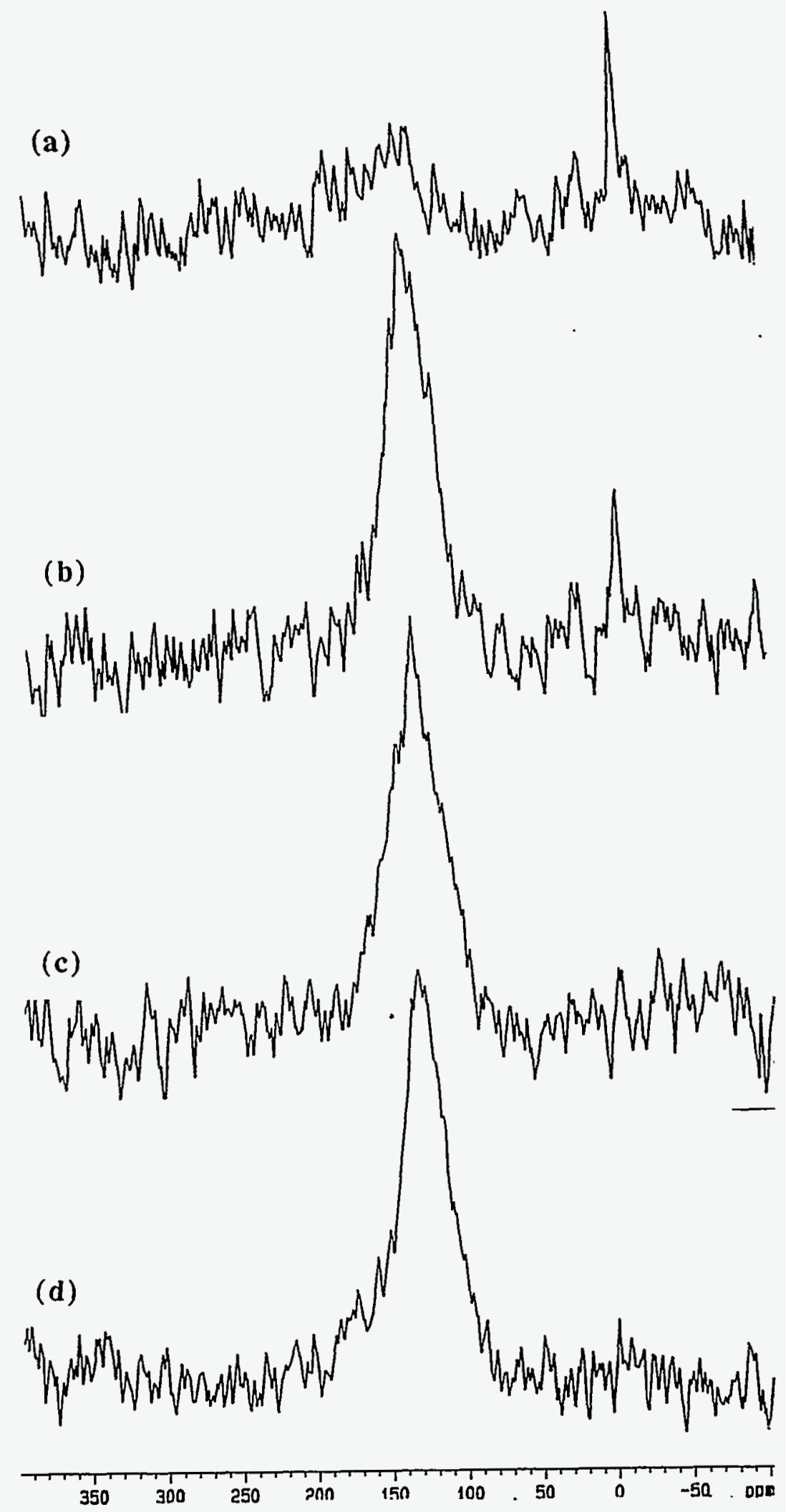

Figure 4. Time dependent ${ }^{129} \mathrm{Xe}$ spectra of Lykens Valley anthracite $40-60$ mesh, run 2. (a) 3 minutes, (b) $4.25 \mathrm{hrs,} \mathrm{(c)} 5.75 \mathrm{hrs,} \mathrm{(d)} 9 \mathrm{hrs}$ from the time the sample was dosed with xenon. The signal at about 0 ppm disappears at about 5.75 hours. 

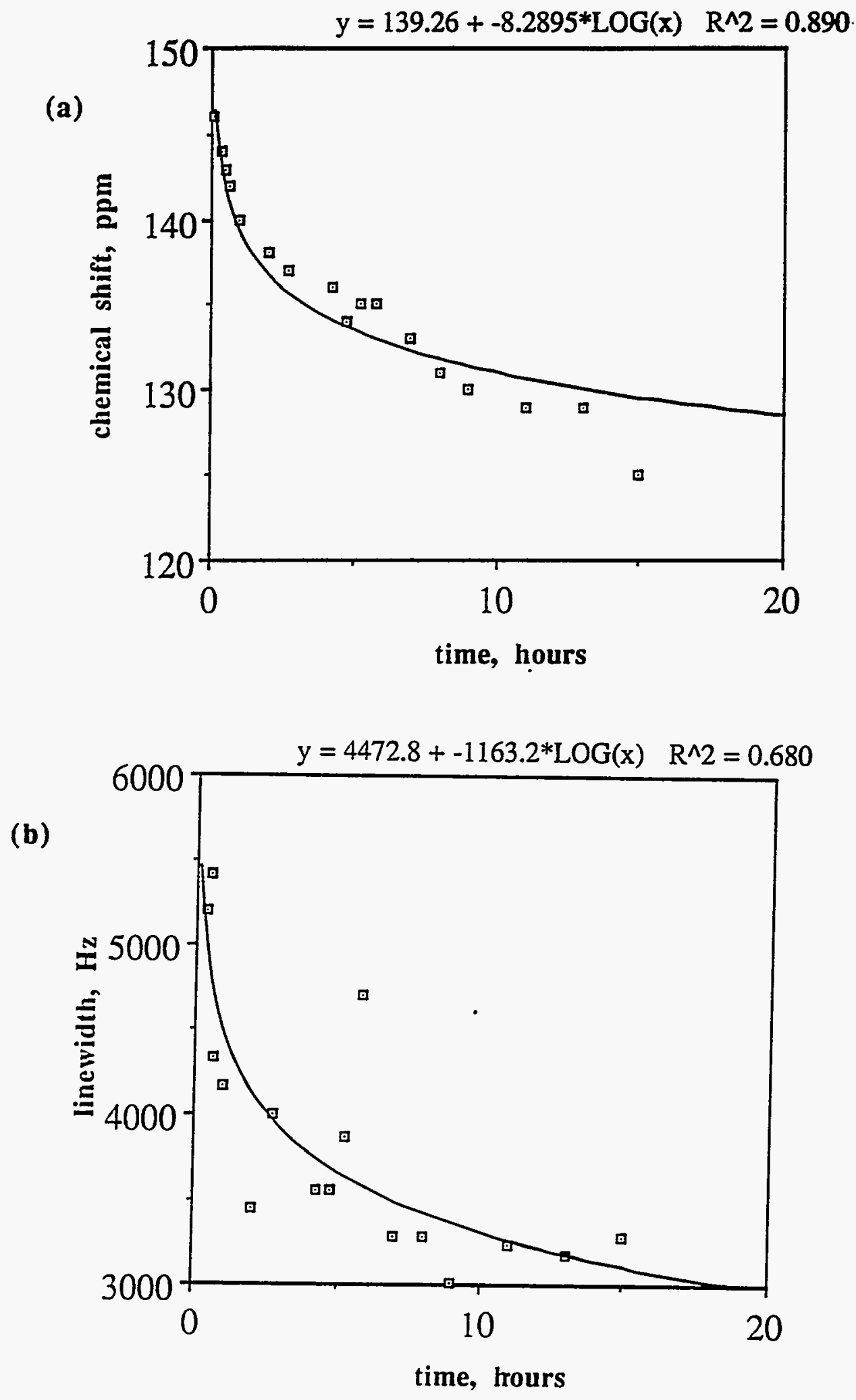

Figure 5. (a) Chemical shift vs. time and (b) linewith vs. time for Lykens Valley anthracite 40-60 mesh, run 2. 


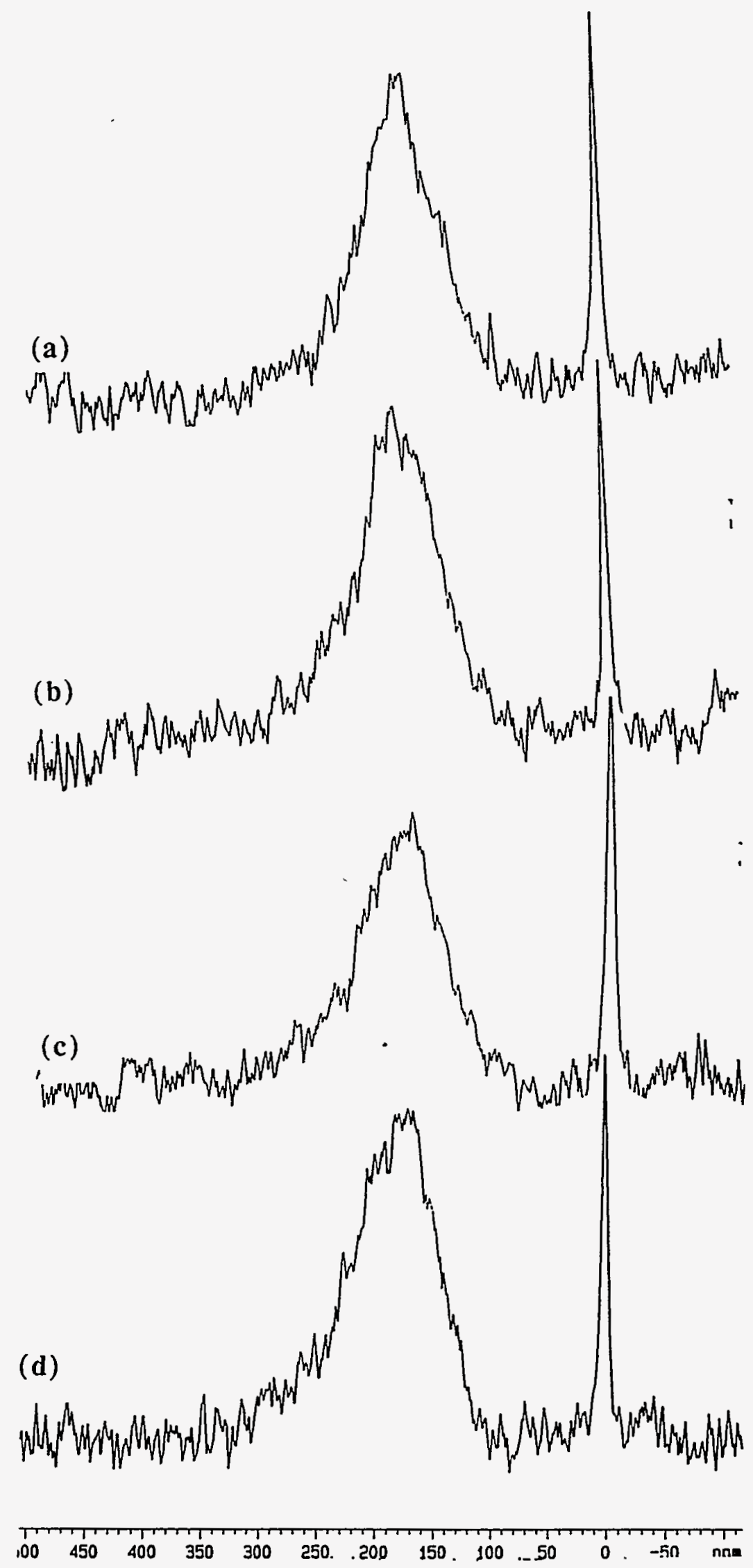

Figure 6. ${ }^{129} \mathrm{Xe}$ spectra of Blind Canyon hvAb coal. (a) 607 torr; (b) 520 torr; (c) 438 torr, (d) 379 torr. 


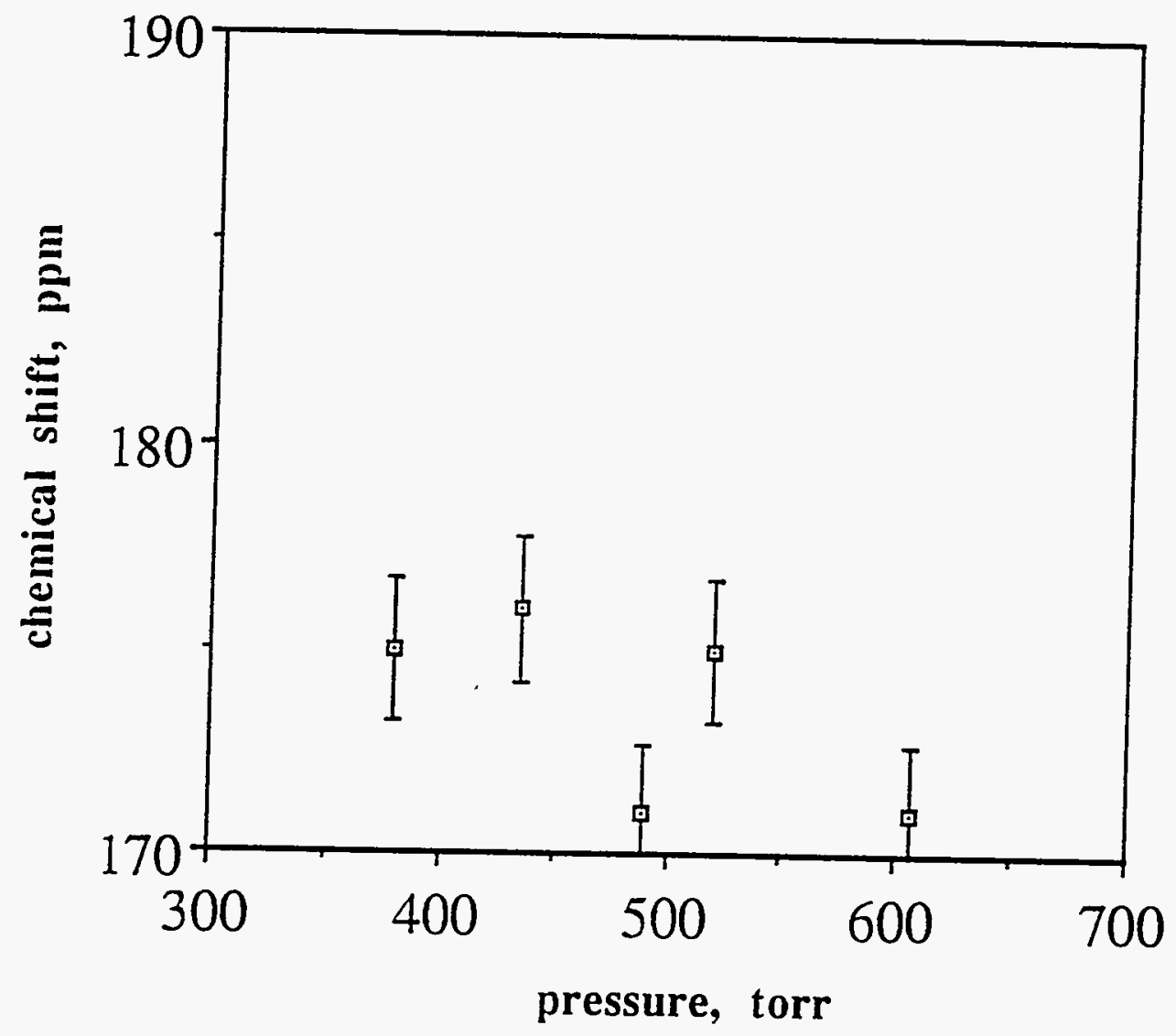

Figure 7. Chemical shift vs. pressure plot for Blind Canyon hvAb coal showing the invariance of chemical shift at these pressures. Error bars representing $1 \%$ error in chemical shift are included. 

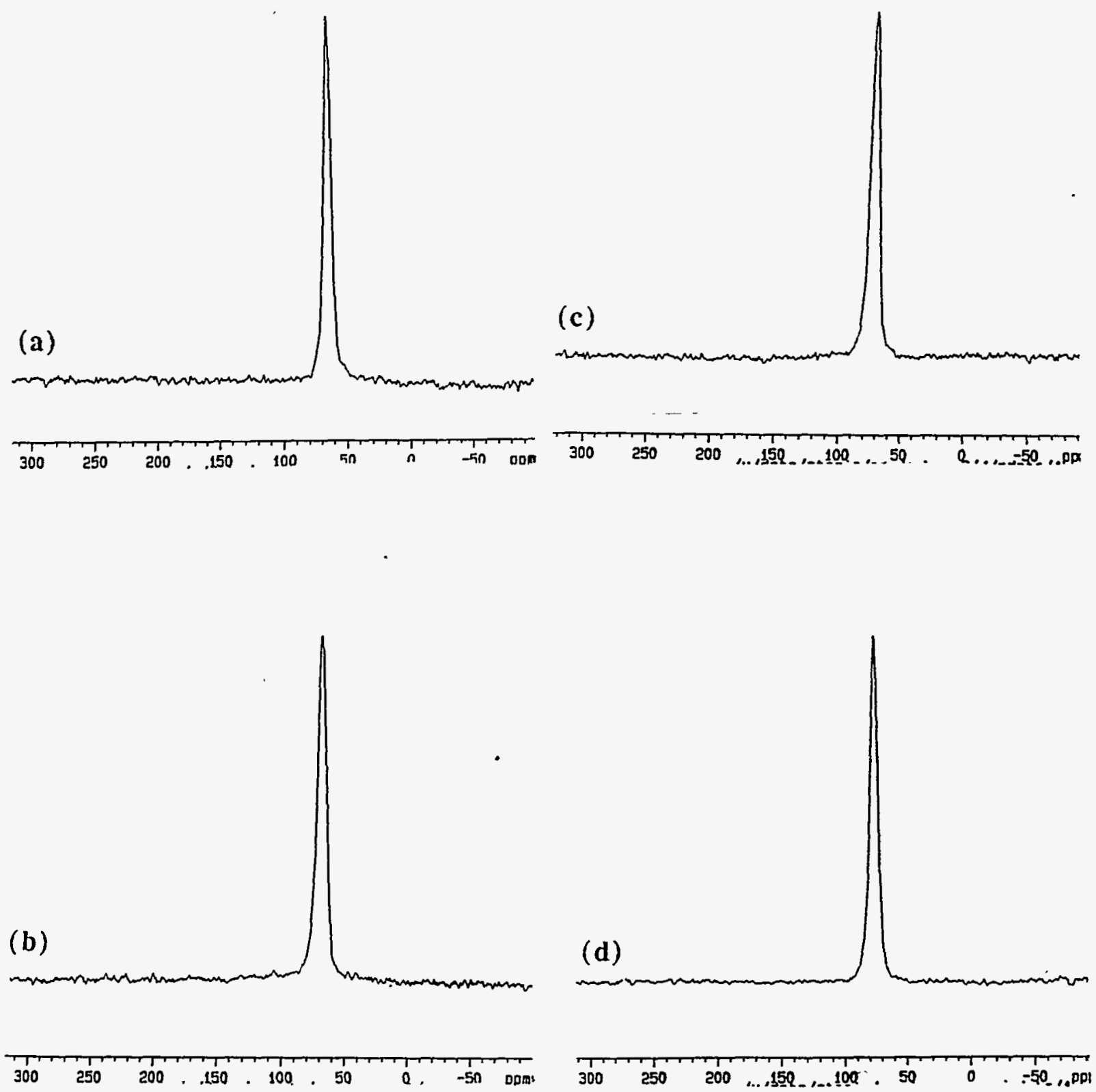

Figure 8. ${ }^{129} \mathrm{Xe}$ spectra of regular Spherocarb, pretreated at $250^{\circ} \mathrm{C}$ under $\mathrm{N}_{2}$. (a) 272 torr Xe; (b) 353 torr; (c) 418 torr, (d) 548 torr. 

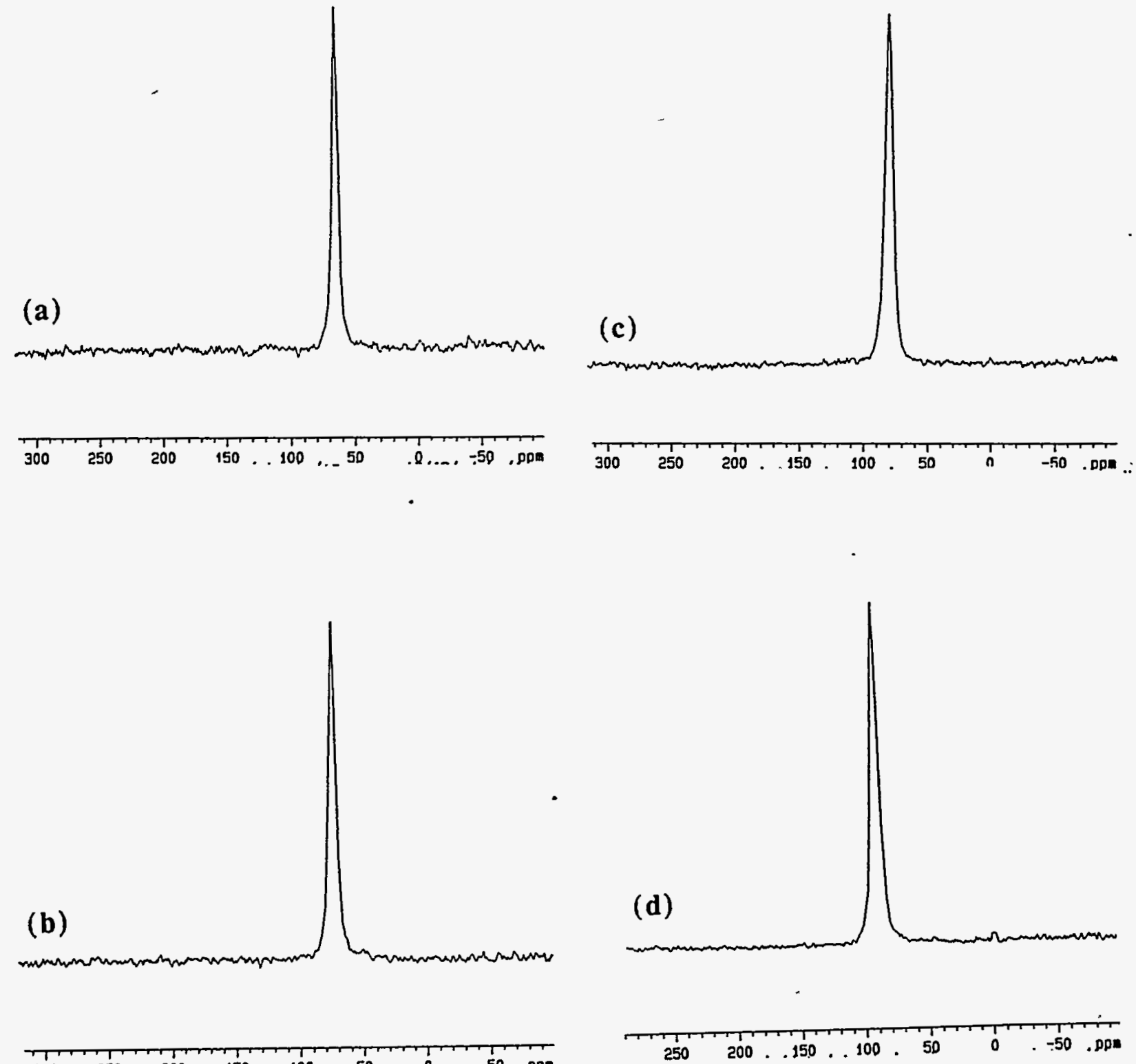

Figure 9. ${ }^{129} \mathrm{Xe}$ spectra of Spherocarb, oxidation \#1, run 2. (a) 273 torr; (b) 367 torr; (c) 595 torr; (d) 660 torr. 

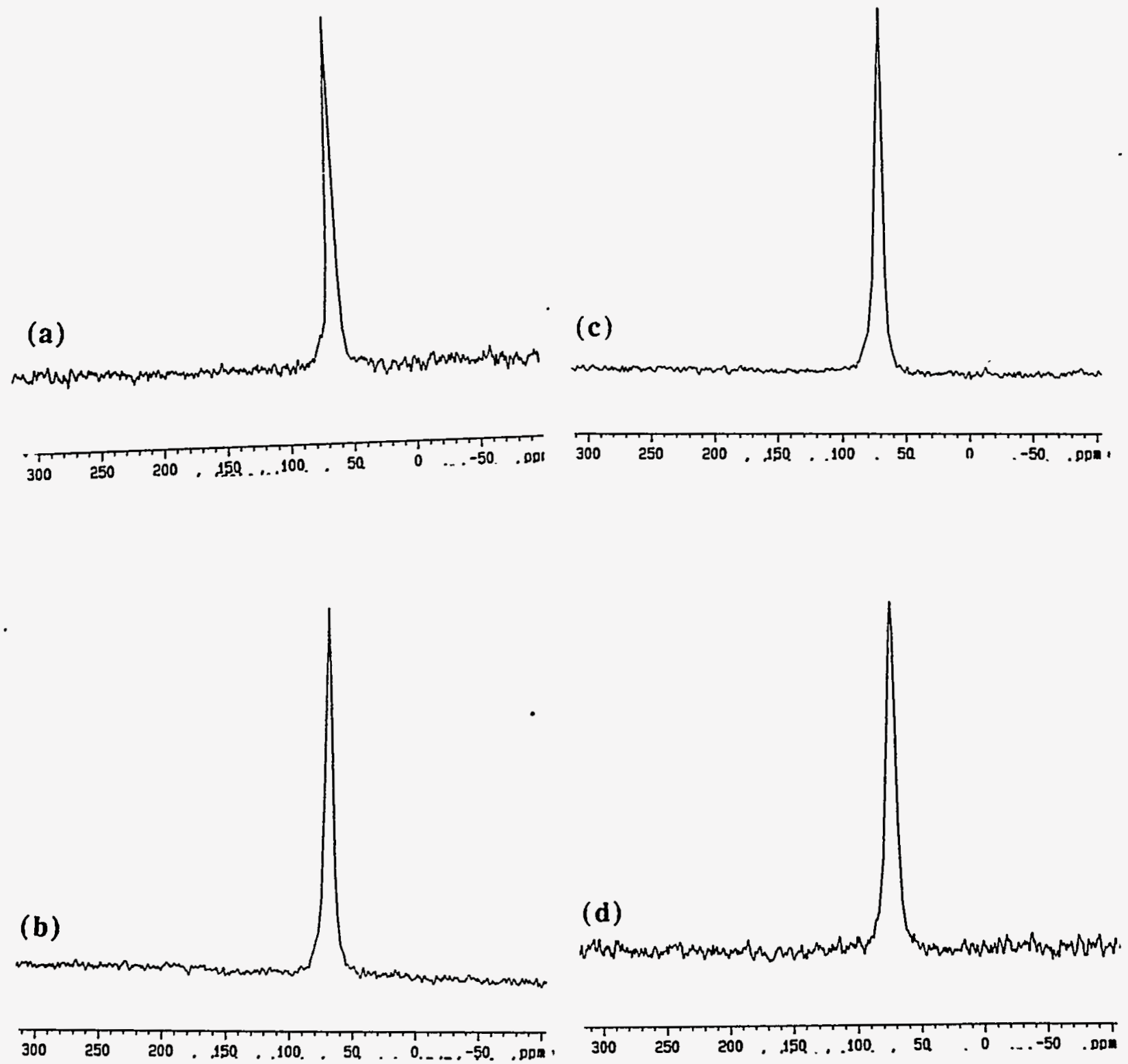

Figure 10. ${ }^{129} \mathrm{Xe}$ spectra of Spherocarb, desorption \#1, run 2. (a) 263 torr; (b) 320 torr; (c) 391 torr; (d) 567 torr. 

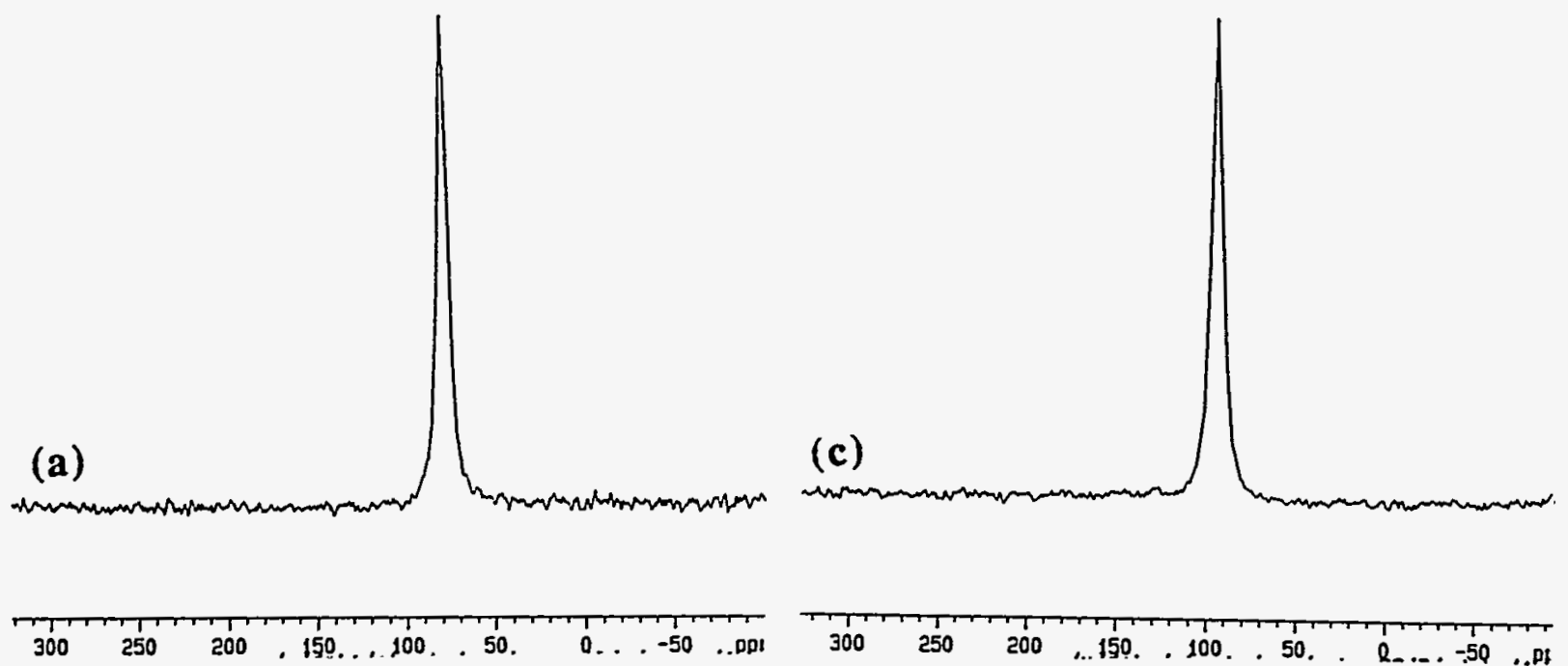

(b)

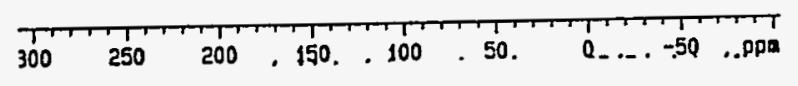

(d)

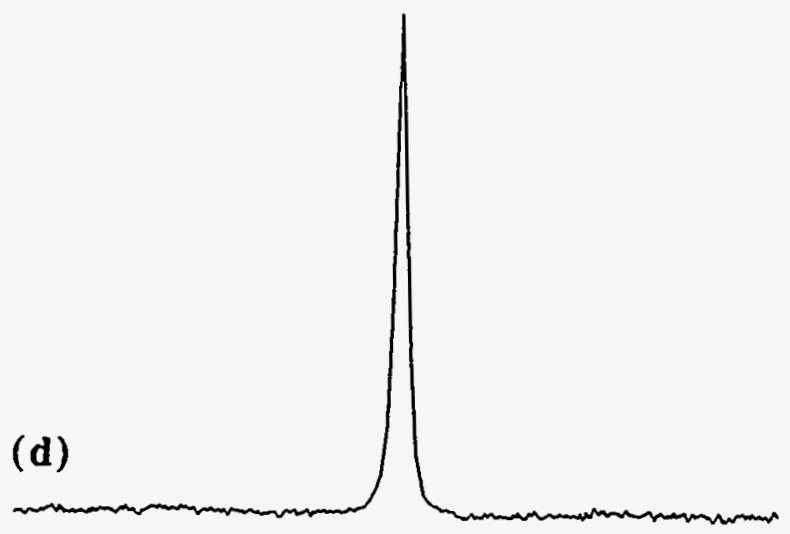

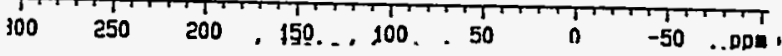

Figure 11. ${ }^{129} \mathrm{Xe}$ spectra of Spherocarb, oxidation \#2, run 2. (a) 267 torr; (b) 415 torr; (c) 576 torr, (d) 737 torr. 

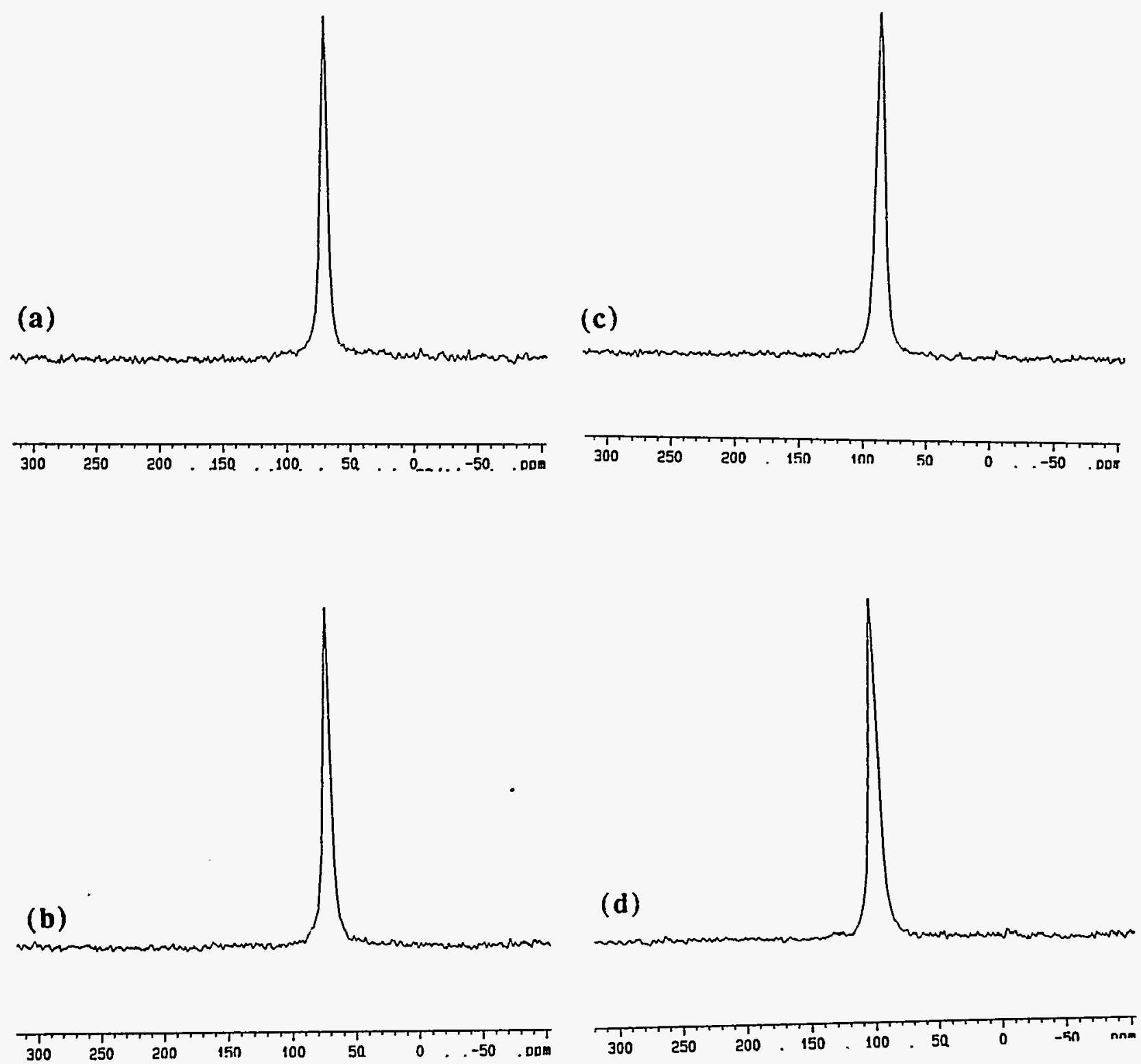

Figure 12. ${ }^{129} \mathrm{Xe}$ spectra of Spherocarb, desorption \#2, run 2. (a) 288 torr; (b) 459 torr; (c) 598 torr; (d) 756 torr. 

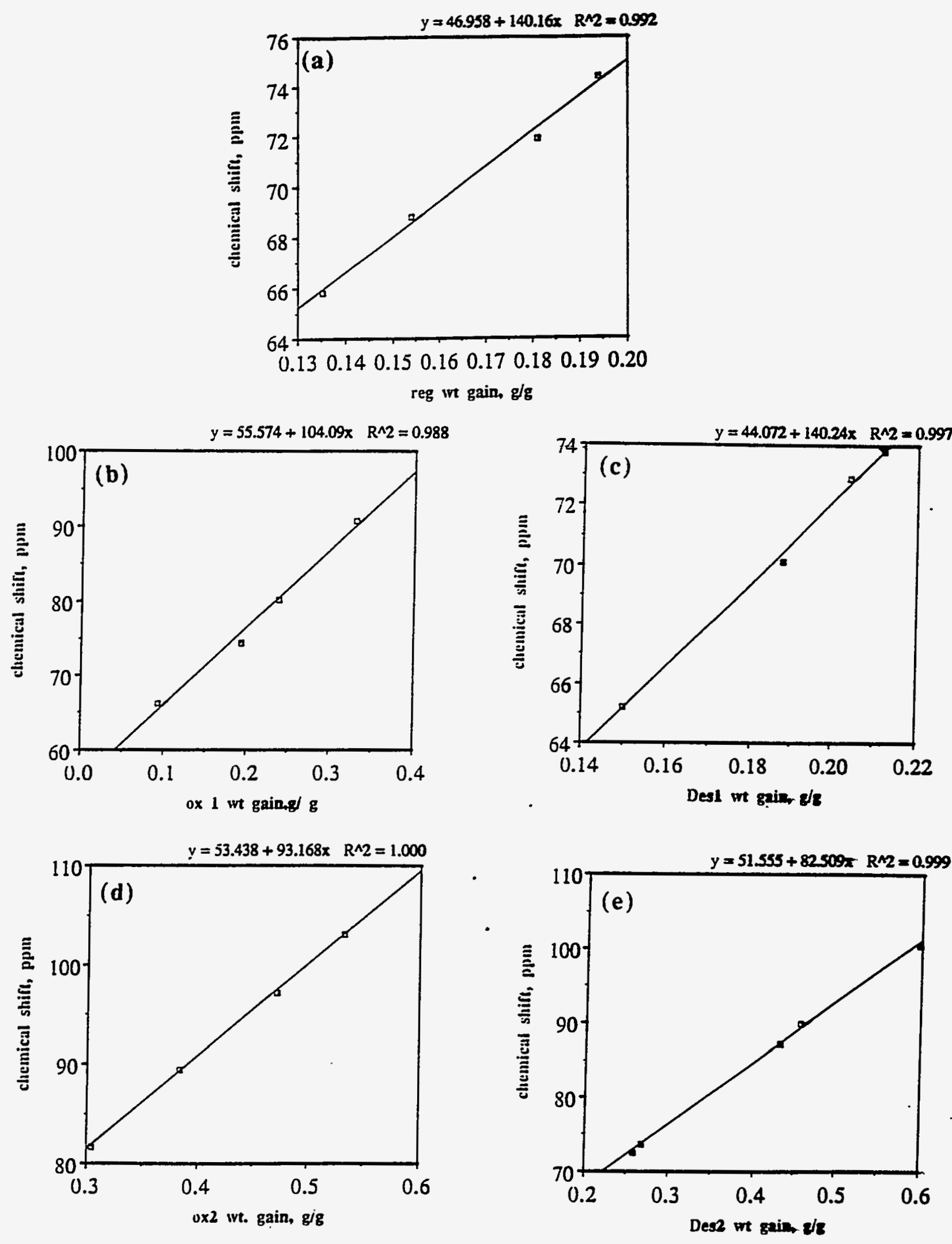

Figure 13. Plots of chemical shift vs. xenon uptake $(\mathrm{g} / \mathrm{g})$ for the series of treatments of Spherocarb. (a) pretreated regular Spherocarb, (b) oxidation 1, (c) desorption 1, (d) oxidation 2, (e) desorption 2. 
(a)
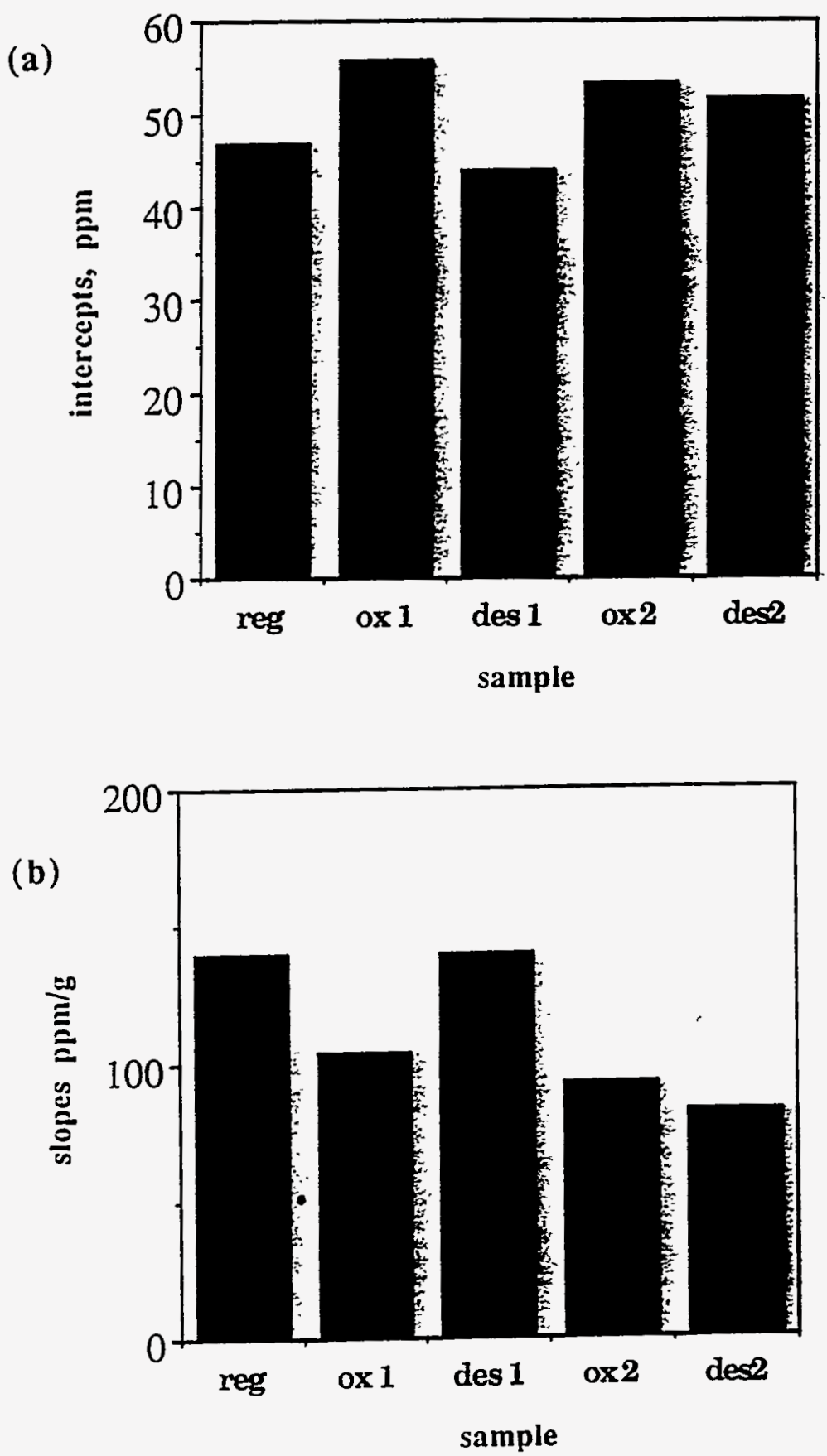

Figure 14. Variation of (a) intercept (ppm) with sample treatment and (b) slope (ppm/gXe/g sample) with sample treatment, of chemical shift vs. uptake plots for the series of treatments of Spherocarb. 


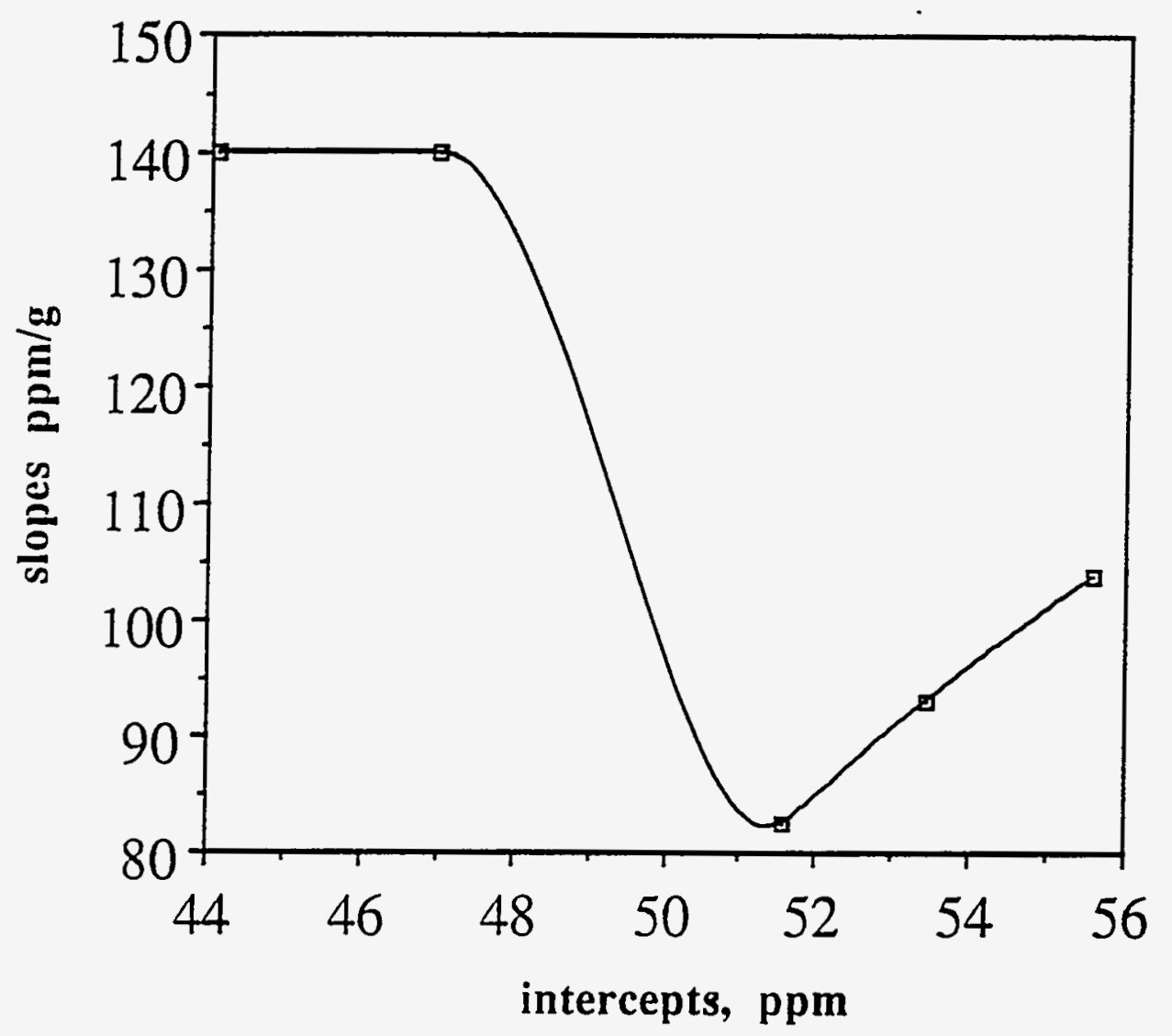

Figure 15. Slope (ppm/gXe/g sample) vs. intercept (ppm) of chemical shift vs. uptake plots for the series of treatments of Spherocarb. 

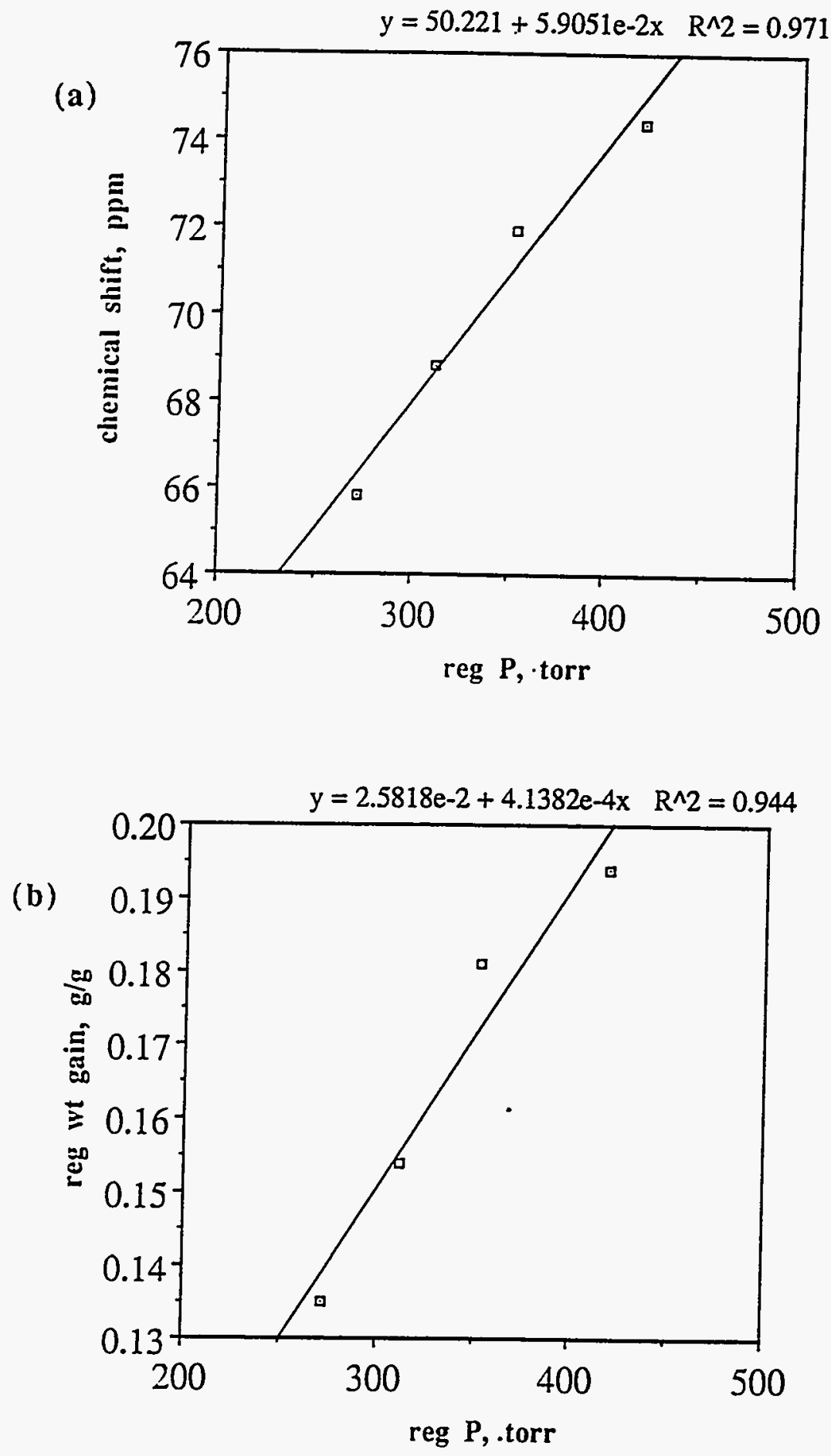

Figure 16. Comparison of (a) Chemical shift vs. xenon pressure, and (b) xenon uptake vs. xenon pressure, for pretreated regular Spherocarb. 
(a)
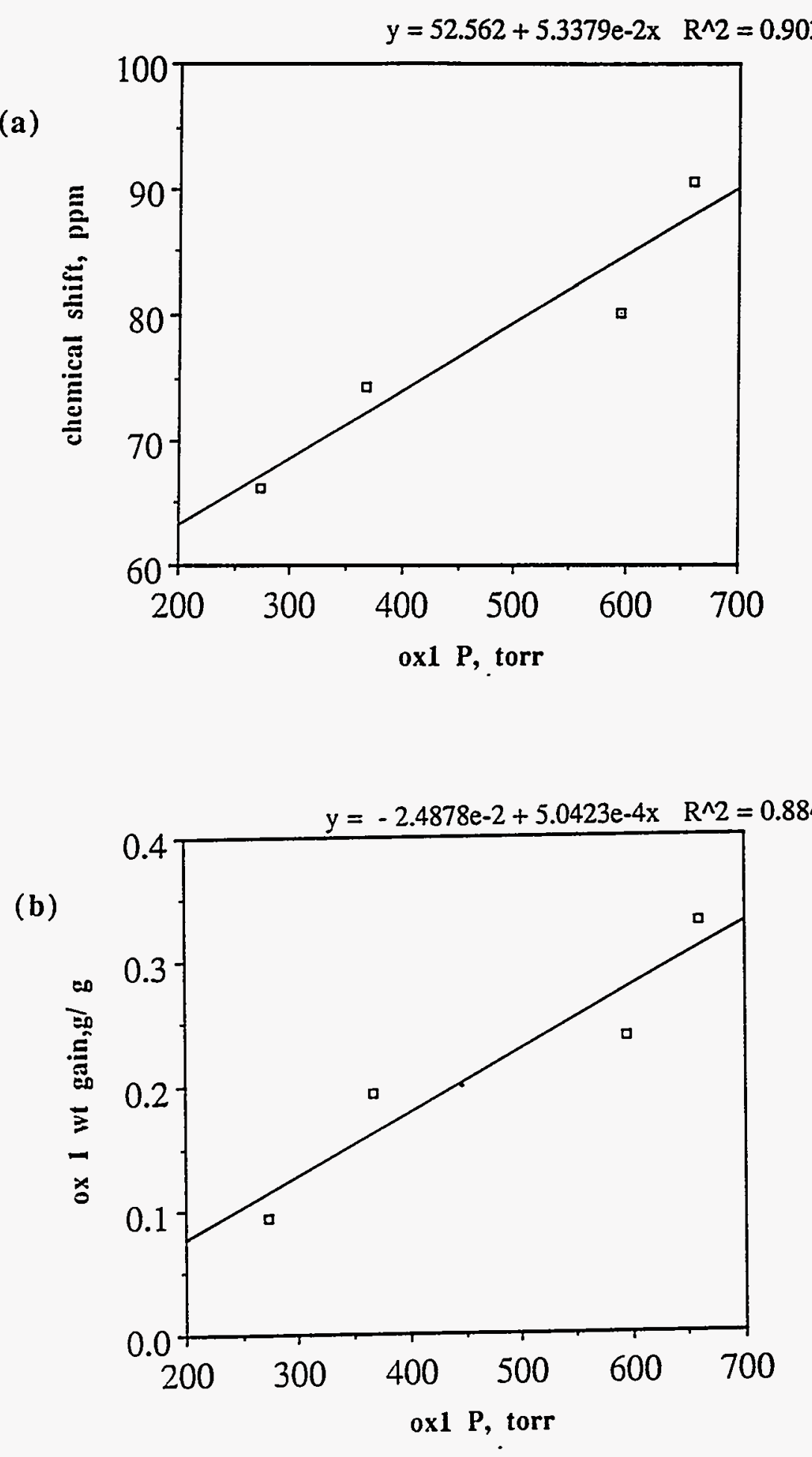

Figure 17. Comparison of (a) Chemical shift vs. xenon pressure, and (b) xenon uptake vs. xenon pressure, for Spherocarb oxidation 1. 
(a)

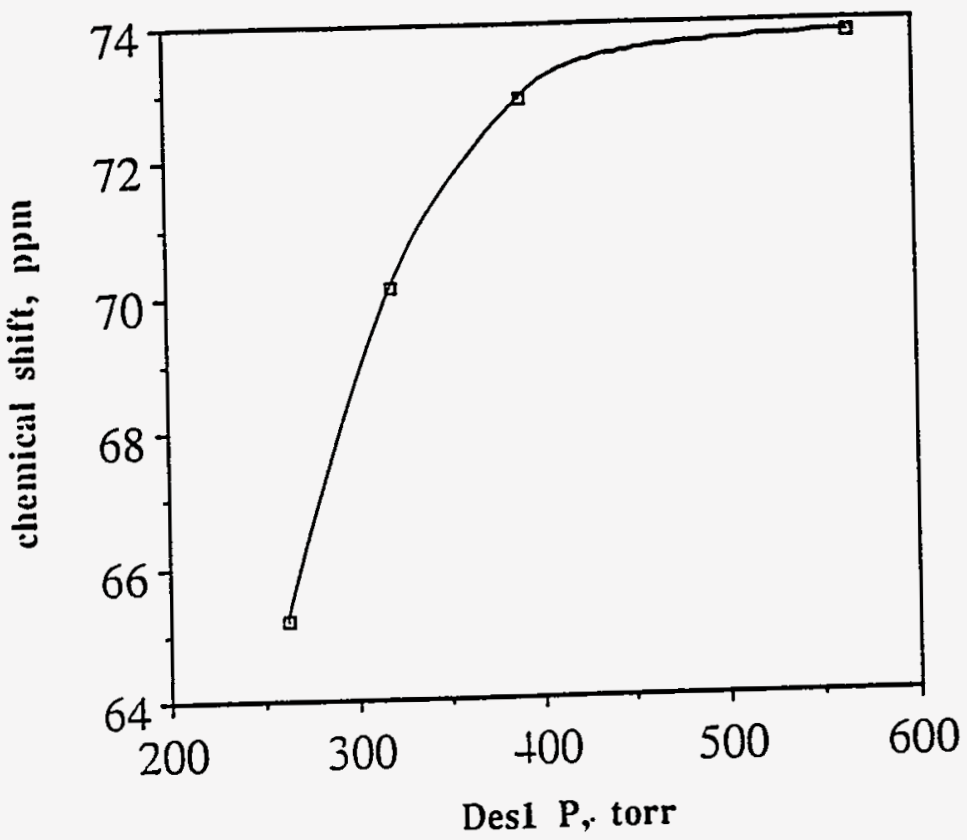

(b)

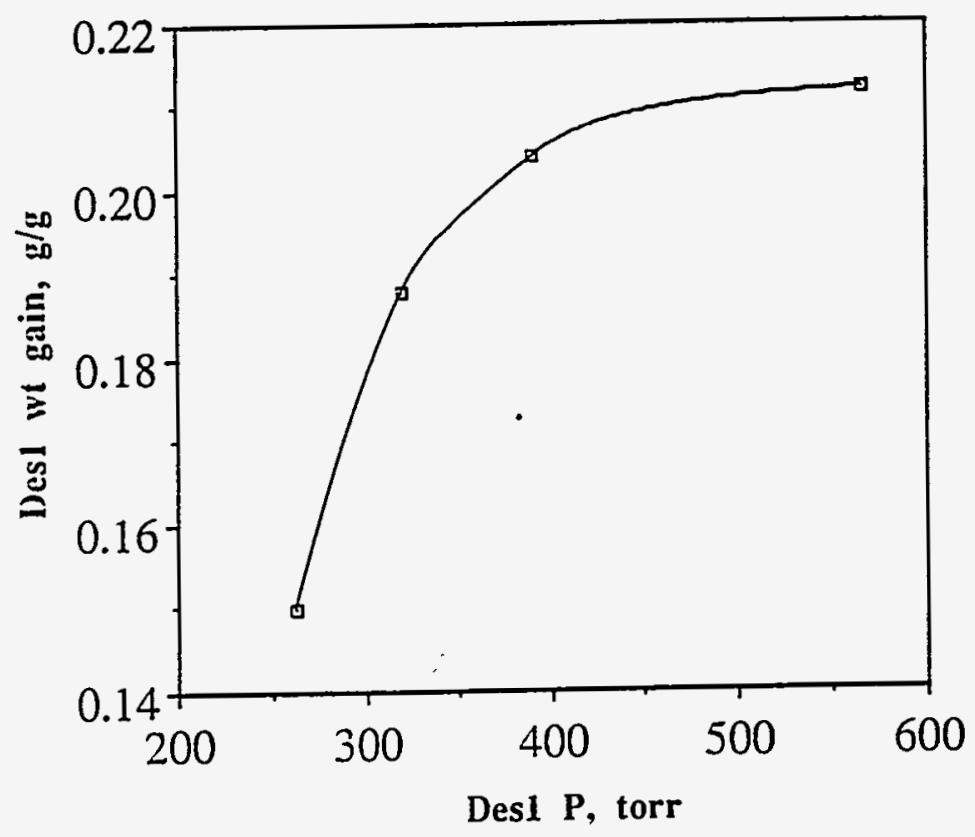

Figure 18. Comparison of (a) Chemical shift vs. xenon pressure, and (b) xenon uptake vs. xenon pressure, for Spherocarb desorption 1. 
(a)
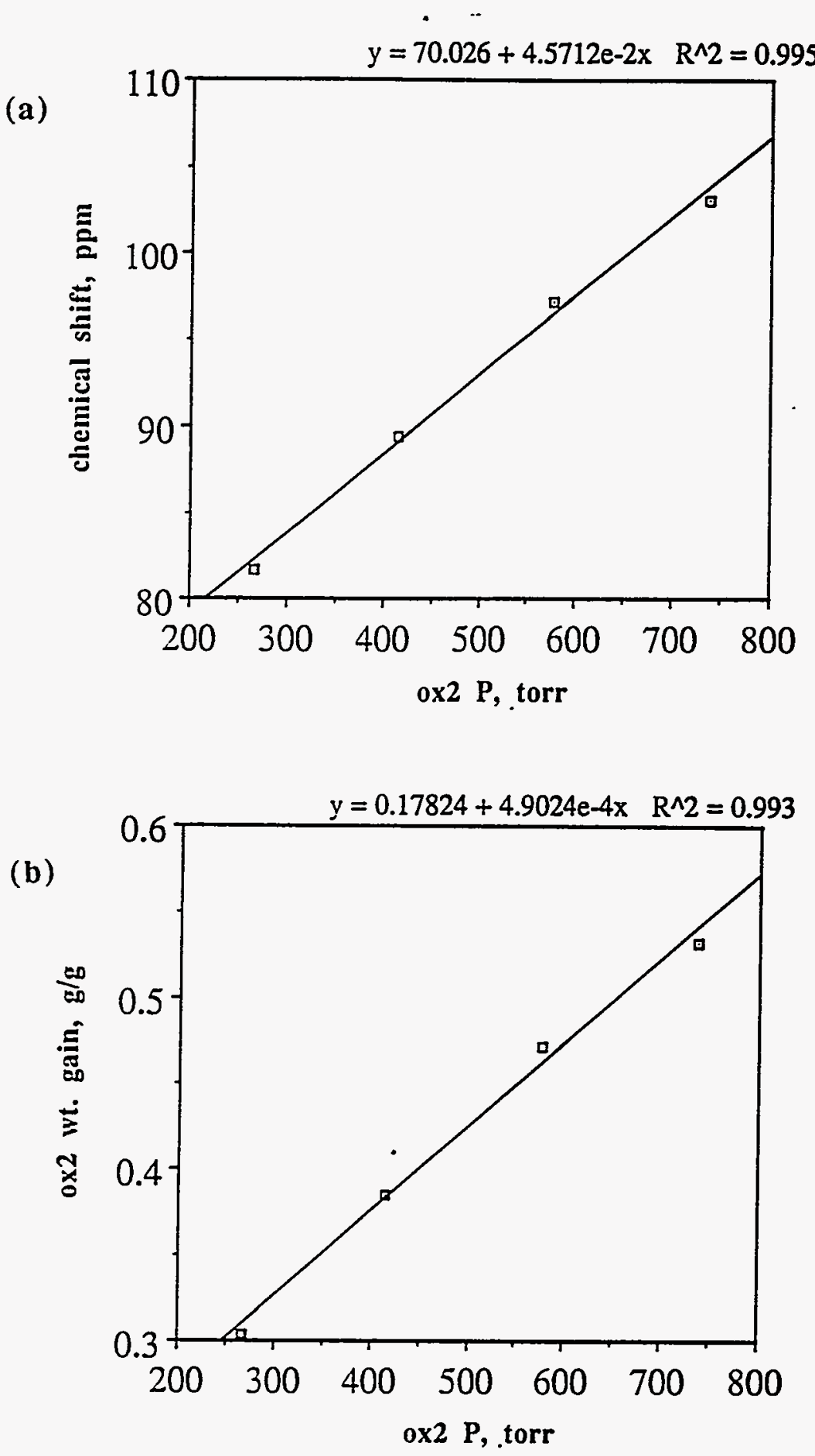

Figure 19. Comparison of (a) Chemical shift vs. xenon pressure, and (b) xenon uptake vs. xenon pressure, for Spherocarb oxidation 2. 

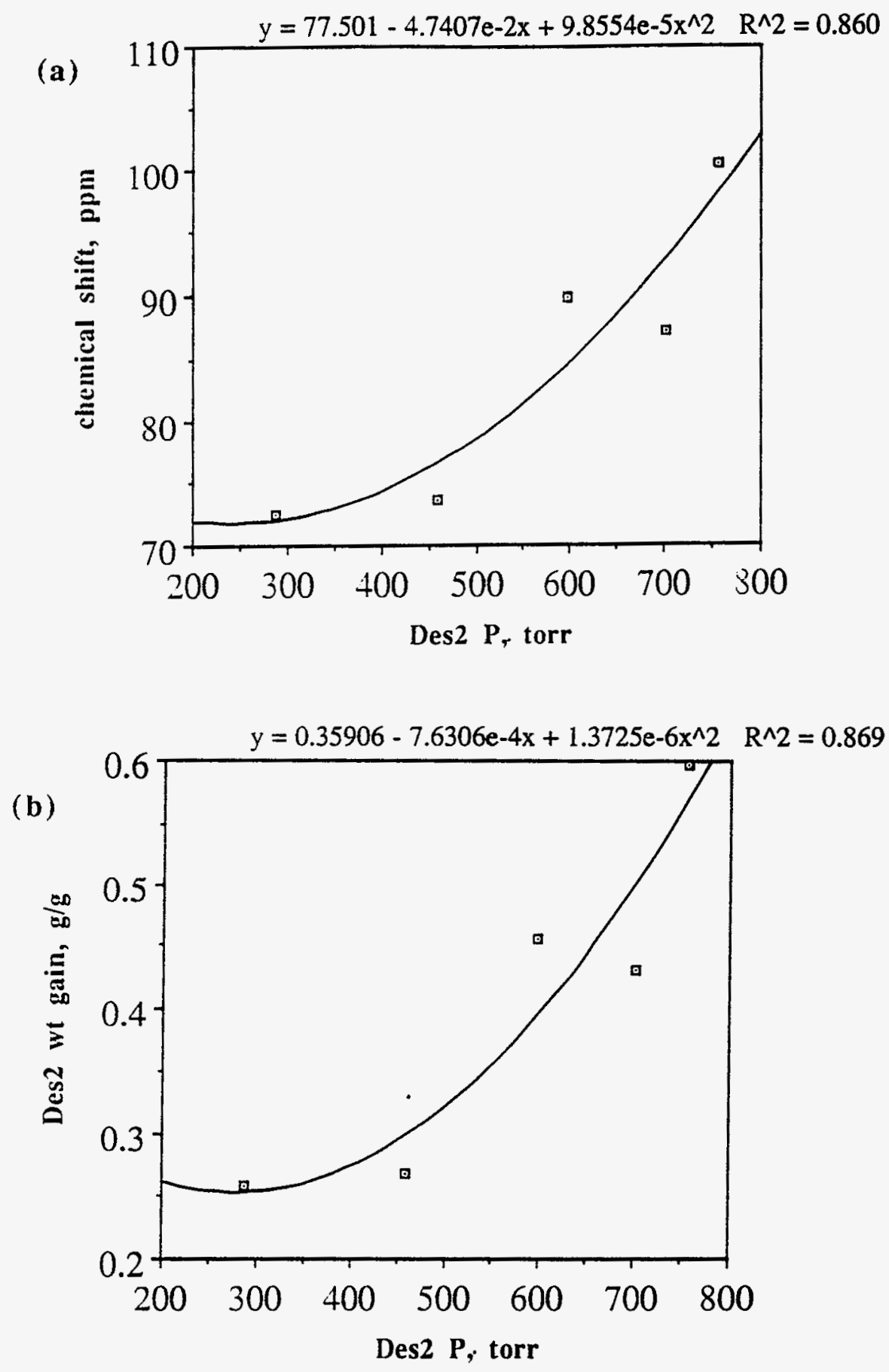

Figure 20. Comparison of (a) Chemical shift vs. xenon pressure, and (b) xenon uptake vs. xenon pressure, for Spherocarb desorption 2. 